\title{
Posttranslational Regulation of Smads
}

\author{
Pinglong $\mathrm{Xu},{ }^{1}$ Xia Lin, ${ }^{2}$ and Xin-Hua Feng ${ }^{1,2,3}$ \\ ${ }^{1}$ Life Sciences Institute and Innovation Center for Cell Signaling Network, Zhejiang University, \\ Hangzhou, Zhejiang 310058, China \\ ${ }^{2}$ Michael E. DeBakey Department of Surgery, Baylor College of Medicine, Houston, Texas 77030 \\ ${ }^{3}$ Department of Molecular \& Cellular Biology, Baylor College of Medicine, Houston, Texas 77030 \\ Correspondence: xhfeng@zju.edu.cn
}

Transforming growth factor $\beta$ (TGF- $\beta$ ) family signaling dictates highly complex programs of gene expression responses, which are extensively regulated at multiple levels and vary depending on the physiological context. The formation, activation, and destruction of two major functional complexes in the TGF- $\beta$ signaling pathway (i.e., the TGF- $\beta$ receptor complexes and the Smad complexes that act as central mediators of TGF- $\beta$ signaling) are direct targets for posttranslational regulation. Dysfunction of these complexes often leads or contributes to pathogenesis in cancer and fibrosis and in cardiovascular, and autoimmune diseases. Here we discuss recent insights into the roles of posttranslational modifications in the functions of the receptor-activated Smads in the common Smad4 and inhibitory Smads, and in the control of the physiological responses to TGF- $\beta$. It is now evident that these modifications act as decisive factors in defining the intensity and versatility of TGF- $\beta$ responsiveness. Thus, the characterization of posttranslational modifications of Smads not only sheds light on how TGF- $\beta$ controls physiological and pathological processes but may also guide us to manipulate the TGF- $\beta$ responses for therapeutic benefits.

$T^{\text {hiting }}$ he transforming growth factor $\beta$ (TGF- $\beta$ ) family consists of structurally related polypeptide dimers that are involved in a diversity of physiological processes in all metazoans. They regulate cell functions, cell and tissue differentiation, and morphogenesis. As a result, deregulation of TGF- $\beta$ family activities leads to or contributes to the pathogenesis of cancer and fibrosis, cardiovascular and autoimmune diseases, and developmental defects.

The signal transduction pathway activated by TGF- $\beta$ family proteins appears quite straightforward. Viewing TGF- $\beta 1$ as the prototype, phosphorylation in the cytoplasmic do- main of the receptor upon TGF- $\beta 1$ binding provides the basis for signal transduction. Ligand binding stabilizes the interaction of TGF$\beta$ type II receptor (T $\beta$ RII) dimers with dimers of the TGF- $\beta$ type I receptor, T $\beta$ RI, also called activin receptor-like kinase 5 (ALK-5), enabling T $\beta$ RII to phosphorylate serines and threonines in the short juxtamembrane Gly-Ser (GS) motifs of TRRI receptors (Souchelnytskyi et al. 1996). This phosphorylation event triggers conformational changes in T $\beta R I$ that allow a surface of T $\beta R I$ to interact with a basic patch of the Mad homology 2 (MH2) domain of the receptor-regulated Smads (R-Smads) and phosphor-

Editors: Rik Derynck and Kohei Miyazono

Additional Perspectives on The Biology of the TGF- $\beta$ Family available at www.cshperspectives.org

Copyright (C) 2016 Cold Spring Harbor Laboratory Press; all rights reserved; doi: 10.1101/cshperspect.a022087

Cite this article as Cold Spring Harb Perspect Biol 2016;6:a022087 
P. Xu et al.

ylation of R-Smads by T $\beta R I$ on distal two serines of the conserved carboxy-terminal SSXS motif (Huse et al. 2001; Shi and Massagué 2003). Subsequently, two phosphorylated RSmads form a heterotrimeric complex with the common Smad4 (co-Smad). The resulting trimeric complex is rapidly translocated into the nucleus where it elicits transcriptional responses (Feng and Derynck 2005; Massagué et al. 2005; Schmierer and Hill 2007). The Smad complex associates with a wide range of DNA-binding transcription factors and cofactors (e.g., coactivators and corepressors) to deliver diverse transcriptional responses on the DNA in a context-dependent manner. Besides the canonical Smad-dependent pathway, ligand binding to cognate receptor complexes also leads to activation of non-Smad signaling pathways, such as mitogen-activated protein kinase (MAPK) pathways and the phosphoinositide 3kinase (PI3K)-Akt-mTOR pathway (Derynck and Zhang 2003). These non-Smad pathways play an important role in some TGF- $\beta$-regulated processes, such as the generation of regulatory Treg $(\mathrm{T})$ and $\mathrm{T}_{\mathrm{H}} 17$ cells (Korn et al. 2009).

All signaling mediators in the TGF- $\beta$ pathway are subject to extensive posttranslational modifications (PTMs). Taking TGF- $\beta$ receptors as examples, a variety of modifications have been identified in recent years. These include phosphorylation (Lawler et al. 1997; Galliher and Schiemann 2007; Lee et al. 2007b), ubiquitylation, sumoylation (Kang et al. 2008), neddylation (Zuo et al. 2013), and ectodomain shedding (Atfi et al. 2007; Liu et al. 2009a; Xu and Derynck 2010; Mu et al. 2011), which contribute to the spatial and temporal regulation in TGF- $\beta$ responsiveness and function in distinct contexts. PTMs of TGF- $\beta$ receptors have been reviewed elsewhere (Xu et al. 2012). We now focus our discussion on the current knowledge of the dynamic regulation of distinct Smads by PTMs, and its pivotal roles in controlling TGF$\beta$ family functions.

\section{POSTTRANSLATIONAL MODIFICATIONS OF R-Smads}

The eight Smads identified in vertebrates comprise five R-Smads. Smad2 and Smad3 are activated in response to stimulation of TGF- $\beta$, nodal, and activin, whereas Smad1, Smad5, and Smad8 respond to bone-morphogenetic proteins (BMPs) and growth and differentiation factors (GDFs) (Heldin and Moustakas 2012). Characterized by a highly conserved amino-terminal MH1 and carboxy-terminal $\mathrm{MH} 2$ domains, and separated by a variable serineand proline-rich linker region, these R-Smads act as main effectors for TGF- $\beta$ family signaling (Shi and Massagué 2003). Like many key signaling mediators, the expression level and activity of R-Smads are under stringent control, particularly through PTMs including (de)phosphorylation, (de)ubiquitylation, sumoylation, (de)acetylation, methylation, and ADP-ribosylation (Fig. 1).

\section{Phosphorylation and Dephosphorylation of R-Smads \\ Phosphorylation of the SSXS Motif by TGF- $\beta$ Type I Receptor and Other Kinases}

R-Smads are activated through ligand-induced phosphorylation by the type I receptors of two serines in their carboxy-terminal SSXS motif. The TGF- $\beta$-specific type I receptor T $\beta R I /$ ALK-5 phosphorylates Smad2 and Smad3, whereas the BMP-specific type I receptors ALK-3/BMPRIA (BMP receptor, type IA) and ALK-6/BMPRIB phosphorylate Smad1, 5, and 8 . This phosphorylation leads to the dissociation of R-Smads from their type I receptors, and homo- or heterodimerization of phosphorylated R-Smads. After association of two R-Smads with Smad4, the R-Smad/Smad4 complexes translocate into the nucleus, in which they elicit transcriptional responses by interacting with a variety of transcription factors and transcriptional coregulators.

In addition to this canonical model of TGF$\beta$ signaling through $\operatorname{Smad} 2$ and $\operatorname{Smad} 3$, some TGF- $\beta$ family ligands were shown to initiate unexpected phosphorylation of a noncanonical R-Smad. Specifically, in addition to the expected Smad2 and Smad3 activation, TGF- $\beta$ induces Smad1 and Smad5 phosphorylation. In endothelial cells, the TGF- $\beta$-specific type I 
Posttranslational Regulation of Smads
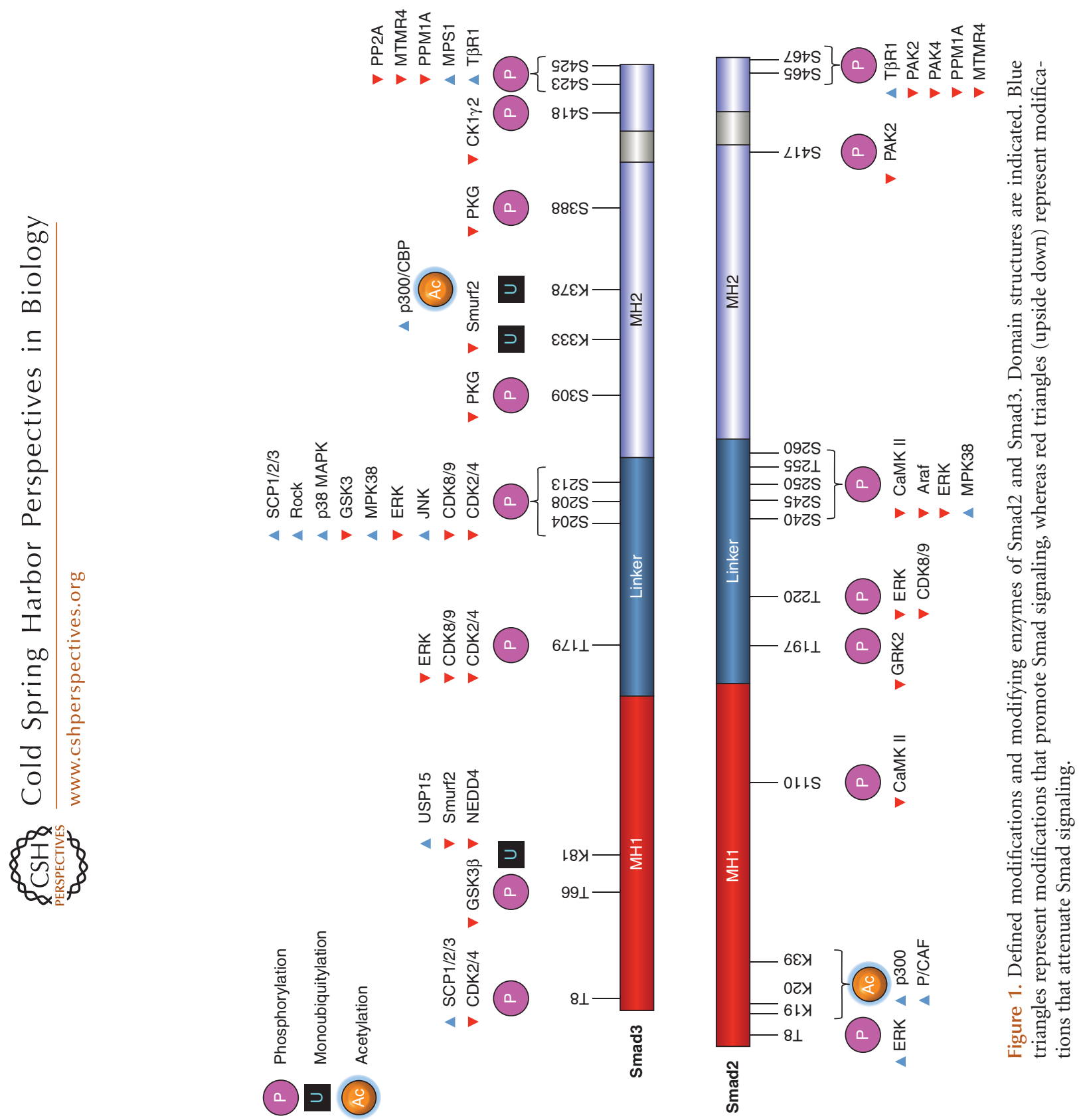
P. Xu et al.

receptor T $\beta R I / A L K-5$ as well as the BMP family type I receptor ALK-1 are essential for TGF$\beta$-induced Smad1 and Smad5 phosphorylation, together with the accessory receptor endoglin (Goumans et al. 2002, 2003; Lebrin et al. 2004). Although T $\beta R I / A L K-5$-mediated Smad 2 and Smad3 activation leads to inhibition of cell migration and proliferation, ALK-1-mediated Smad1 and Smad5 activation results in opposite effects. Therefore, a fine balance between T $\beta R I / A L K-5$ and ALK-1 signaling defines the roles of TGF- $\beta$ in endothelium (Goumans et al. 2002, 2003; Lebrin et al. 2004). A similar scenario is also observed in dermal fibroblasts, in which TGF- $\beta$ stimulates Smad1 phosphorylation and Smad1-mediated transcription of collagen and other target genes, depending on both T $\beta$ RI/ALK-5 and ALK-1, and activation of extracellular signal regulated kinases 1 and 2 (Erk1/2) MAP kinases (Pannu et al. 2007). Additionally, T $\beta R I / A L K-5$ and canonical Smad1 activation by BMP family type I receptors are required for TGF- $\beta$-induced Smad1 and Smad5 phosphorylation in keratinocytes and fibroblasts. The phosphorylation of Smad1 and Smad5 endows carcinoma cells with a motile and invasive phenotype, and anchorage-independent growth (Bharathy et al. 2008; Daly et al. 2008). More strikingly, TGF$\beta$-induced Smad 1 and Smad5 phosphorylation was shown to be independent of BMP receptors and essential for the TGF- $\beta$-induced migration of mammary epithelial cells (Liu et al. 2009b; Wrighton et al. 2009b). These studies therefore reveal the functional significance of the cross talk between TGF- $\beta$ ligand and the normally BMP-regulated R-Smads, and the roles of TGF- $\beta$-induced Smad1 and Smad5 phosphorylation in a cell type-dependent manner, because TGF- $\beta$ stimulates, but does not inhibit, the proliferation of endothelial cells under certain conditions (Goumans et al. 2003), and TGF- $\beta$ appears to be essential for anchorageindependent growth of epithelial cells (Daly et al. 2008).

In addition to the canonical phosphorylation by type I receptor kinase, the carboxy-terminal SSXS motif of R-Smads can also be phosphorylated by other kinases distinct from the type I TGF- $\beta$ family receptor kinases. For example, Mps1, a kinase that regulates mitotic progression, can phosphorylate the SSXS motif of Smad2 and Smad3, although it is unclear whether it activates the Smad pathway (Zhu et al. 2007). The oncogenic kinase p21 protein-activated kinase 4 (PAK4) can phosphorylate Ser465 in the SSXS motif of Smad2, which leads to Smad2 proteasomal degradation. Accordingly, a marked increase in phospho-S465 Smad2 level, concomitant with a lower total Smad2 protein level, has been observed in gastric cancer tissues (Wang et al. 2014a). The physiological significance of R-Smad phosphorylation and activation by these kinases remains to be further explored.

\section{Dephosphorylation of the SSXS Motif}

With the carboxy-terminal SSXS phosphorylation of R-Smads as the first essential step in activating Smad-mediated transcription, some mechanisms inhibit the activation of R-Smads to terminate R-Smad functions. These include phosphatase-mediated dephosphorylation, ubiquitylation-dependent degradation, and nuclear export of R-Smads. A low level of continuous dephosphorylation allows for disassembly of the Smad complex and subsequent nuclear export of R-Smads (Inman et al. 2002; Xu et al. 2002b). Several phosphatases mediate phospho-SSXS dephosphorylation. PPM1A (protein phosphatase, $\mathrm{Mg}^{2^{+}} / \mathrm{Mn}^{2^{+}}$-dependent, 1A)/PP2C $\alpha$ (protein phosphatase-2C $\alpha$ ), the prototype of PPM family phosphatases, preferentially binds and dephosphorylates the phospho-SSXS motif of not only Smad2 and Smad3, but also of the BMP-specific Smad1 and Smad5 (Duan et al. 2006; Lin et al. 2006). PPM1A limits the duration of the R-Smad activity in the nucleus in both the TGF- $\beta$ - and BMP-activated Smad pathways, and thus attenuates TGF- $\beta$ - and BMP-regulated transcriptional responses, and TGF- $\beta$ /nodal-stimulated effects on cell growth arrest and early embryogenesis of zebrafish (Duan et al. 2006; Lin et al. 2006).

Interestingly, phosphatase and tensin homolog (PTEN), a negative regulator of the PI3K/Akt pathway, serves as a cofactor of 
PPM1A to enhance the abrogation of $\operatorname{Smad} 2 / 3$ phosphorylation by stabilizing PPM1A, suggesting an intriguing cross talk between sphingolipid and TGF- $\beta$ signaling pathways ( $\mathrm{Bu}$ et al. 2008). MAN1, also known as LEMD3, an integral protein of the inner nuclear membrane, associates with PPM1A in the dephosphorylation of Smad2 and Smad3 (Bourgeois et al. 2013). Inactivation of the gene encoding MAN1/LEMD3 leads to developmental anomalies in a mouse model, whereas heterozygous loss-of-function mutations in humans cause sclerosing bone dysplasia (Bourgeois et al. 2013). In addition, the dual-specificity protein phosphatase MTMR4, identified as a phosphatase that dephosphorylates PI3P, was also reported to dephosphorylate the phospho-SSXS motif of Smad2 and Smad3 in endosomes and to repress the TGF- $\beta$ response (Yu et al. 2010). Using RNAi-mediated gene silencing screening, protein pyruvate phosphatase (PDP) (Chen et al. 2006) and small carboxy-terminal domain phosphatases (SCPs) (Knockaert et al. 2006) were found to increase the carboxy-terminal phosphorylation of Drosophila Mad, the homolog of Smad1 and Smad5, or Smad1. Therefore, the expression of PDP enhances decapentaplegic (Dpp)- or BMP-stimulated target gene expression, whereas the expression of SCPs leads to induction of a secondary dorsal axis in Xenopus (Knockaert et al. 2006). However, ectopically increased expression of mammalian PDPs or SCPs does not affect phospho-Smad1 dephosphorylation (Duan et al. 2006). Another SCP family phosphatase, SCP4/CTDSPL2, physically interacts with and dephosphorylates Smad1, Smad5, and Smad8, thus attenuating BMP-induced transcriptional responses and osteogenic differentiation in C2C12 cells (Zhao et al. 2014). Phosphatase PP2A under hypoxic conditions can dephosphorylate the phospho-SSXS motif of Smad3, but not Smad2, thus suggesting a mechanism by which a hypoxia condition regulates TGF- $\beta$ responses (Heikkinen et al. 2010b). Remarkably, CLIC4, a multifunctional protein that shuttles between the cytoplasm and nucleus, can associate with activated Smad2 and Smad3 to protect them from dephosphorylation of their phospho-SSXS motif, which is required for TGF- $\beta$ signaling and TGF- $\beta$-induced growth inhibition of epithelial cells (Shukla et al. 2009).

Dephosphorylation and subsequent disassembly of the Smad complexes often lead to nuclear export of R-Smads (Inman et al. 2002; Xu et al. 2002a; Shi and Massagué 2003; Schmierer and Hill 2005). A mathematical model has been proposed for how Smad phosphorylation and dephosphorylation, complex formation, and nucleocytoplasmic shuttling work together to transduce TGF- $\beta$ signals (Schmierer et al. 2008). The nuclear transport cofactor Ranbinding protein 3 (RanBP3) directly recognizes the dephosphorylated Smad2 and Smad3, and mediates their nuclear export in a Ran-dependent manner to inhibit TGF- $\beta$ responses in mammalian cells and Xenopus embryos (Dai et al. 2009). RanBP3L was found to be responsible for recognition and nuclear export of Smad1, Smad5, and Smad8, which regulate the osteogenesis of mesenchymal stem cells (Chen et al. 2015). Remarkably, PPM1A can also dephosphorylate RanBP3 to enable efficient nuclear export of Smad2 and Smad3 (Dai et al. 2011). Besides nuclear export of dephosphorylated R-Smads, activated R-Smads also undergo faster degradation in the nucleus (Lo and Massagué 1999; Izzi and Attisano 2004; Mavrakis et al. 2007).

The complexity of phosphorylation and dephosphorylation of the SSXS motif by multiple kinases and phosphatases highlights the critical role of SSXS phosphorylation in TGF- $\beta$ family signaling. Further studies are required to better define how the Smad kinases and phosphatases exert their activities and how these processes are controlled by cellular contexts.

\section{Linker Region Phosphorylation of R-Smads}

Besides rapidly inducing phosphorylation of RSmads at their carboxy-terminal SSXS motif, TGF- $\beta$ also induces linker phosphorylation, at three other sites, in Smad3 but with a slower kinetics (Millet et al. 2009). The linker region of R-Smads, that is, the less conserved sequence between the amino-terminal MH1 domain and the carboxy-terminal MH2 domain, can also be phosphorylated on Ser/Thr in response to oth- 
P. Xu et al.

er growth factors and by various kinases, which consequently regulate R-Smad activities (Derynck and Zhang 2003; Feng and Derynck 2005). Given the flexible nature of the R-Smad linker region, different phosphorylation patterns may impose conformational interfaces that may affect protein-protein interactions and functions of both MH1 and MH2 domains (Sapkota et al. 2007). Mitogens and hyperactive Ras lead to Erk1/2-mediated linker phosphorylation of Smad3 at Ser204, Ser208, and Thr179. Mutation of these sites often promotes activation of target genes by Smad3, suggesting that the MAPK-mediated Smad3 linker phosphorylation is inhibitory for Smad3 activity (Kretzschmar et al. 1999; Lehmann et al. 2000), although oppositely stimulating effects have also been reported (Lehmann et al. 2000). Studies in mice carrying mutations in the potential MAPK phosphorylation sites of Smad1 also support an inhibitory role of linker phosphorylation on Smad1, because mice bearing these mutants show defects in gastric epithelial homeostasis (Aubin et al. 2004). Additional kinases, for example, casein kinase (CK) $1 \gamma 2, \mathrm{CK} 1 \varepsilon$, calcium/calmodulin-dependent protein kinase II (CaMK II), protein kinase C (PKC), and MAP kinase kinase-1 (MEKK-1), also phosphorylate the R-Smad linker regions and down-regulate Smad-dependent transcriptional responses (Wrighton and Feng 2008). In contrast, phosphorylation of the linker region of Smad3 by p38 MAPK and Rho-associated, coiled coil kinase (ROCK) (Ser204, Ser208, and Ser213), or by c-Jun amino-terminal kinase (JNK) (Ser208 and Ser213), enhances the transcriptional activity of Smad3 to generate a more robust TGF- $\beta$ response (Engel et al. 1999; Mori et al. 2004; Kamaraju and Roberts 2005). All of these data illustrate the direct cross talk between the TGF$\beta /$ Smad signaling pathway and other signaling pathways.

Furthermore, deleted in liver cancer 1 (DLC1), a StAR-related lipid transfer protein, whose gene is frequently inactivated in tumor cells and is seen as a candidate tumor suppressor gene, blocks Rho-ROCK-mediated Smad3 linker phosphorylation and inhibits the TGF- $\beta$-induced expression of parathyroid hormone-like hormone (PTHLH), which promotes osteoclast maturation for osteolytic colonization (Wang et al. 2014b). As a result, silencing the expression of DLC1 in cancer cells promotes bone metastasis and leads to osteolysis and accelerated death in mice. Additionally, a with no lysine (WNK) family kinase WNK1, originally identified as a kinase upstream of Erk5 MAPK (Lee et al. 2007a), and murine protein serine-threonine kinase 38 (MPK38) (Seong et al. 2010), also directly phosphorylate Smad2. Thus, depletion of WNK1 increases the accumulation of activated Smad2 in the nucleus and enhances the transcription of TGF- $\beta$ target genes, whereas knockdown of MPK38 inhibits TGF- $\beta$ signaling, and TGF- $\beta$-induced apoptosis and growth arrest in epithelial cells (Seong et al. 2010). GRK2, a kinase that together with $\beta$-arrestins desensitizes many $G$ protein-coupled receptors by regulating their internalization and trafficking, also associates with Smad2 and Smad3 and phosphorylates their linker regions (Ho et al. 2005). GRK2-mediated linker phosphorylation inhibits TGF- $\beta$ ligand-induced carboxy-terminal SSXS phosphorylation through an as-yet-unknown mechanism, and prevents nuclear translocation and transcriptional activity of the Smad complex, as well as TGF- $\beta$-stimulated apoptosis and growth inhibition in primary hepatocytes (Ho et al. 2005). Additionally, a Raf family member of kinase, Araf, was also found to phosphorylate Ser253 in the linker region of Smad2 and to attenuate Smad2 signaling by accelerating its degradation (Liu et al. 2013). Thus, silencing Araf expression in zebrafish results in increased accumulation of mesendoderm precursors and a dorsalized phenotype.

In the nucleus, Smad3 is phosphorylated by the cyclin-dependent kinases (CDK)2 and CDK4 at Thr8, Thr179, and Ser213. This phosphorylation inhibits the transcriptional activity of Smad3 and the antiproliferative effect of TGF- $\beta$ (Matsuura et al. 2004). It thus confers cancer-cell resistance to TGF- $\beta$-induced growth-inhibitory effects. Remarkably, a significant increase in Ser208/Ser213 phosphorylation of Smad3 is associated with late stage colorectal tumors, indicating that Smad3 linker phosphorylation may contribute to the tumor- 
promoting role of TGF- $\beta$ (Yamagata et al. 2005). Taken together, the linker region of R-Smads is emerging as an important and critical regulatory platform for fine-tuning of TGF- $\beta$ responses and cross talk with other signaling pathways.

Linker Region Phosphorylation and Dephosphorylation and R-Smad Degradation

Glycogen synthase kinase 3 (GSK3), a downstream effector of Wnt signaling, and the CDK family kinases CDK8 and CDK9 phosphorylate and mark activated Smad2 or Smad3 for proteasomal destruction (Alarcon et al. 2009; Millet et al. 2009; Wang et al. 2009). Following phosphorylation, the PPXY motif in the linker region is recognized by the E3 ubiquitin ligase neural precursor cell expressed, developmentally down-regulated 4-like (Nedd4L), also known as Nedd4-2, which then polyubiquitylates Smad2 or Smad3 and targets them for proteosome-mediated degradation (Gao et al. 2009). Thus, linker phosphorylation limits the half-life of activated Smads, and the amplitude and duration of TGF- $\beta$ responses, as it is apparent from the induction of mesendodermal fates in mouse embryonic stem cells (mESCs). Similarly, the duration of Smad1 activation is controlled by sequential linker phosphorylation at the conserved MAPK and GSK3 recognition sites, and in turn controls the intensity of BMP signals during embryonic pattern formation (Fuentealba et al. 2007). Notably, CDK8 and $\mathrm{CDK} 9$ also phosphorylate the linker region of Smad1, enabling the recruitment of the transcription factor Yes-associated protein (YAP), an effector of the Hippo pathway. They also phosphorylate the linker region of Smad2 and Smad3, allowing recruitment of the peptidylprolylisomerase Pinl that isomerizes phosphoserine/threonine-proline motifs and thus enhances Smad-mediated transcription. YAP consequently promotes Smad1-dependent transcription and controls BMP-mediated suppression of neural differentiation of mESCs (Alarcon et al. 2009). This phosphorylation is ultimately recognized by the E3 ubiquitin ligase Smad ubiquitin regulatory factor 1 (Smurf1) or Nedd4L and leads to Smad degradation (Alar- con et al. 2009; Aragon et al. 2011). The switch from initial activation to subsequent destruction appears to result from the recognition of Smad phosphoserines by WW (Trp-Trp) domains of YAP or Pin1 and the E3 ubiquitylating ligases (Aragon et al. 2011). For example, CDK8- and CDK9-mediated Smad3 linker phosphorylation creates binding sites for WW domains of Pin1, whereas subsequent phosphorylation by GSK3 switches off Pin1 binding but generates binding sites for Smurf1 WW domains (Aragon et al. 2011).

Cancer cells often possess high levels of MAPK and CDK activities that lead to a higher phosphorylation level in the R-Smad linker region. A comprehensive study indicates that mutation in the Smad3 linker phosphorylation sites markedly inhibits primary tumor growth, but significantly increases lung metastasis of breast cancer cells, which is in line with the inhibitory role of TGF- $\beta$ in tumor initiation and TGF- $\beta$ 's promotion of tumor migration (Bae et al. 2014). This is also in consistent with earlier findings that mutation of CDK2, CDK4, and Erk phosphorylation sites in the linker regions of Smad 2 and Smad 3 enhances the TGF- $\beta$ response and functions (Kretzschmar et al. 1999; Matsuura et al. 2004, 2005).

The discovery of R-Smad linker phosphatases further illustrates the complexity of linker phosphorylation and supports the notion that linker phosphorylation and dephosphorylation are dynamic processes that are subject to tight regulation. For example, the SCP family phosphatases SCP1, 2, and 3 can remove the linker and $\mathrm{MH} 1$ domain phosphorylations of Smad2 and Smad3, with no effect on the carboxy-terminal SSXS phosphorylation of Smad3, and hence reverse the inhibitory effect of these phosphorylations (Sapkota et al. 2006; Wrighton et al. 2006). Likewise, SCP1, SCP2, and SCP3 can also dephosphorylate the linker of Smad1, thereby, suggesting their critical roles in regulating TGF- $\beta$ family signaling and, consequently, their biological effects, such as TGF- $\beta$-stimulated cell growth inhibition, and TGF- $\beta /$ BMPregulated transcriptional responses in mammalian cells and in Xenopus embryos (Sapkota et al. 2006; Wrighton et al. 2006). 
P. Xu et al.

\section{Phosphorylation of the $\mathrm{MH} 1$ and $\mathrm{MH} 2$ Domains of R-Smads}

In association with the scaffolding protein Axin, GSK3 $\beta$ phosphorylates the MH1 domain of the nonactivated form of Smad3, which results in Smad3 ubiquitylation and subsequent degradation, and thus defines the basal level and activity of Smad3, and the cell sensitivity to TGF- $\beta$ (Guo et al. 2008a). In contrast, Erk-dependent phosphorylation of Smad2 at the amino-terminal Thr8 site enhances the transcriptional activity of Smad2 by an unknown mechanism (Funaba et al. 2002). Additionally, PKG (cGMPdependent protein kinase) in endothelial cells (Saura et al. 2005) and CK1 12 in mouse embryonic fibroblasts or epithelial cells (Guo et al. $2008 \mathrm{~b}$ ) induce the phosphorylation of Smad3 MH2 domains at Ser388 or Ser418 to enhance Smad ubiquitylation and degradation. Additionally, PAK2 induces Smad2 phosphorylation at Ser417 to block its association with T $\beta R I$ (Yan et al. 2012), all leading to inhibition of TGF- $\beta$-stimulated gene expression. Whether additional phosphorylation sites in the R-Smads and other kinases are involved in these activities remains to be determined.

\section{Ubiquitylation and Deubiquitylation of R-Smads}

\section{Ubiquitin E3 Ligases for Polyubiquitylation and Degradation of R-Smads}

Ubiquitylation, that is, the covalent attachment of a chain of ubiquitin polypeptides onto the polypeptide substrate results from the sequential actions of E1, E2, and E3 ubiquitin ligases, and defines the turnover and functions of diverse proteins in a wide range of biological processes (Kerscher et al. 2006). Like many other transcription regulators, $\mathrm{R}-\mathrm{Smads}$ are regulated by ubiquitylation and ubiquitin-like modifications that serve to control the subcellular localization, stability, and activity of Smads. TGF- $\beta$-induced Smad2 activation is followed by polyubiquitylation, which targets nuclear Smad2 for degradation and terminates its signaling (Lo and Massagué 1999). Several ubiquitin ligases have been implicated in R-Smad degradation, including the homologous E6AP carboxy-terminal (HECT) family E3 ligases Smurf1, Smurf2, Nedd4-2/Nedd4L, and WWP1 (WW domain-containing protein 1), the RING-finger family E3 ligase SCF complex (Rbx1, Skp1, Cullins, F-box proteins) and Arkadia (also known as RNF111), and the U-box family E3 ligase carboxyl terminus of Hsc70interacting protein (CHIP) (Soond and Chantry 2011; Tang and Zhang 2011).

The ubiquitin E3 ligases named "Smad ubiquitin regulatory factor (Smurf)" were the first identified ubiquitin E3 ligases for Smads, and have been well studied. They target RSmads, inhibitory Smads (I-Smads), as well as some Smad-associated proteins for proteasomal degradation (Feng and Lin 2006; Izzi and Attisano 2004). Specifically, Smurf1 ubiquitylates the BMP-specific Smad1 and Smad5, and marks them for degradation without affecting TGF- $\beta$-specific Smad2 and Smad3 (Zhu et al. 1999). The related Smurf2 shows broader substrate specificity and physically associates with Smad1 and Smad2, resulting in their degradation (Lin et al. 2000; Zhang et al. 2001). Besides Smurf1 and Smurf2, distantly related members of WW-containing HECT family E3 ligases such as WWP1/Tiull and Nedd4-2/Nedd4L also control Smad stability (Komuro et al. 2004; Seo et al. 2004; Kuratomi et al. 2005). In contrast, Itch/AIP4, a Smurf2-like E3 ligase, enhances TGF- $\beta$ signaling and TGF- $\beta$-induced cell growth arrest through an as yet undefined mechanism (Bai et al. 2004).

Surprisingly, Smad3 is not targeted for destruction by Smurf proteins although it has high affinity for Smurf2, but instead is targeted by a different family of ubiquitin E3 ligases (i.e., Skp1-cullin-F-box [SCF] proteins) (Fukuchi et al. 2001; Ray et al. 2005). For example, the interaction of Smad3 with $\mathrm{ROC1} / \mathrm{Rbx} 1$, the Ring subunit of $\mathrm{SCF}^{\beta \operatorname{TrCP}}$ complex, is partly responsible for Smad3 degradation (Fukuchi et al. 2001). Smad 3 is also targeted by CHIP, a U-box family E3 ligase, which ubiquitylates and degrades Smad3 independently of TGF- $\beta$ stimulation and reduces the TGF- $\beta$ response, including the control of cell proliferation by TGF- $\beta$ (Xin et al. 2005). Additionally, during mouse 
Posttranslational Regulation of Smads

embryogenesis, Arkadia/RNF111, a nuclear RING-domain E3 ubiquitin ligase, which was initially shown to ubiquitylate Smad7 and the Smad corepressor SnoN (Levy et al. 2007), also directly interacts with phospho-Smad2 and -Smad3, and enhances their levels in mouse embryonic cells. This association is followed by phospho-Smad2 and Smad3 ubiquitylation that leads to their proteasomal degradation, thus resulting in down-regulation of nodal signaling (Mavrakis et al. 2007).

As the best studied Smad E3 ligases, the functions of Smurfs in Smad signaling are also supported by observations in pathophysiological contexts. Transgenic analysis supports the role of Smurf1 in the destruction of BMP-specific Smad1 and Smad5. Osteoblast-specific expression of a Smurf1 transgene in mice indeed leads to a significant reduction in bone mass during postnatal life (Zhao et al. 2004). However, transgenic mice with increased expression of Smurf1 in chondrocytes fail to show clear abnormalities (Horiki et al. 2004). These data suggest that Smurfl plays a specific role in bone development. Unexpectedly, targeted disruption of the Smurf1 gene in mice does not affect Smad-mediated TGF- $\beta$ or BMP signaling, and Smurf1-deficient mice are born normally (Yamashita et al. 2005). However, these mice show an age-dependent increase of bone mass and enhanced activities of osteoblasts (Yamashita et al. 2005). Additionally, mouse lung branching morphogenesis can be inhibited by adenoviral expression of Smurfl in airway epithelial cells (Shi et al. 2004a). Mice that lack a functional Smurf2 gene display defects in planar cell polarity and extension movement, through changes in noncanonical Wnt signaling pathway, but without obvious changes in TGF- $\beta$ family signaling (Narimatsu et al. 2009). Therefore, the in vivo significance of Smurf proteins in TGF- $\beta$ family signaling is complex and requires further investigation.

Increased expression of Smurf2 correlates with reduced levels of Smads under various disease conditions. For example, increased Smurf2 expression with a concomitantly reduced level of phospho-Smad2 is observed in esophageal cancers (Fukuchi et al. 2002). Similarly, elevated expression of Smurf2 parallels the ubiquitylation and degradation of Smad 2 in rat glomeruli, leading to glomerulonephritis (Togawa et al. 2003). However, increased expression of Smurf1 and Smurf2 may also lead to Smad7 degradation, which, in turn, increases the TGF- $\beta$ response and plays a pathogenic role in the progression of renal fibrosis (Fukasawa et al. 2004).

\section{Role and Regulation of R-Smad Ubiquitylation by Phosphorylation}

As mentioned, TGF- $\beta$-induced linker phosphorylation marks activated Smads for proteasomal destruction, mediated by the activity of the E3 ubiquitin ligase Nedd4L (Gao et al. 2009). Nedd4L thus limits the half-life of TGF$\beta$-activated Smads and restricts the intensity and duration of TGF- $\beta$ signaling, and the induction of mesendodermal fates in mESCs. Similarly, Smurf1 selectively binds to Smad1, following phosphorylation of its linker region, further illustrating the interplay between phosphorylation and polyubiquitylation in mouse osteoblast differentiation and Xenopus neural development (Sapkota et al. 2007). Additionally Smad3 phosphorylation at Ser418 in its MH2 domain by CK1 $\gamma 2$ targets activated Smad3 for ubiquitylation-dependent degradation and decreases TGF- $\beta$ responsiveness (Guo et al. 2008 b), although the responsible E3 ubiquitin ligase has not been identified. Ubiquitylationmediated degradation occurs preferentially with the nonactivated form of Smad3. For example, GSK3 $\beta$-dependent phosphorylation of nonactivated Smad3 at Thr66 in the MH1 domain is essential for ubiquitylation and subsequent degradation of Smad3 (Guo et al. 2008a). This ubiquitylation leads to reduction of total Smad3 level, thus decreasing the sensitivity of cells to TGF- $\beta$. The sequential roles and interplay of phosphorylation and ubiquitylation provide extensive control of TGF- $\beta$ signaling.

R-Smads can also function as adaptors of E3 ubiquitin ligase to facilitate the ubiquitylation and degradation of associated proteins by the E3 ligase. For example, TGF- $\beta$ induces the formation of a ternary complex consisting of Smad2, SnoN, and Smurf2, in which Smad2 
P. Xu et al.

serves as an adaptor that enables the Smurf2 E3 ligase to target SnoN for degradation (Bonni et al. 2001). This degradation relieves SnoNmediated suppression of TGF- $\beta$ targets in the absence of TGF- $\beta$ ligand. The degradation of SnoN is also regulated by anaphase-promoting complex (APC) (Stroschein et al. 2001; Wan et al. 2001). In this case, Smad3 binds to both SnoN and APC, and cooperates with the APC activator Cdc20 homologue-1 (CDH1) to promote SnoN ubiquitylation and degradation by APC. In another example, Smad3 physically associates with the cell-cycle regulator Cdc25A and the $\mathrm{SCF}^{\beta \operatorname{TrCP}} \mathrm{E} 3$ ligase in response to TGF$\beta$, thus facilitating $\mathrm{SCF}^{\beta \operatorname{TrCP}}$-mediated $\mathrm{Cdc} 25 \mathrm{~A}$ ubiquitylation and degradation (Ray et al. 2005). Thus, the stabilization of Cdc25A observed in various cancers might be related to dysregulation of the TGF- $\beta / \operatorname{Smad} 3$ pathway.

\section{Monoubiquitylation of $R$-Smads}

Monoubiquitylation, whereby a protein is modified by covalent attachment of a single ubiqutin at a single or multiple lysines, regulates the signaling function of the substrates. Smad2 and Smad3 are monoubiquitylated in response to TGF- $\beta$; however, the effect of this monoubiquitylation differs depending on context. The HECT family E3 ligase Itch/AIP4 forms a complex with Smad2 and the activated form of T $\beta R I$, and monoubiquitylates Smad2, which in turn enhances Smad2 interaction with T $\beta R I$ and TGF- $\beta$-induced cell growth arrest (Bai et al. 2004). In contrast, Smad3 was shown to be monoubiquitylated in its MH1 domain at multiple lysine residues, possibly by Smurf 2 or Nedd4, and these modifications interfere with Smad3 binding to the regulatory promoter sequences of target genes and block Smad3-mediated cell growth arrest, cell migration, and embryonic germ layers induction and patterning in Xenopus (Inui et al. 2011). Different from controlling Smad1 and Smad2 stability through polyubiquitylation, Smurf2-mediated Smad3 monoubiquitylation of the $\mathrm{MH} 2$ domain interferes with the formation of functional Smad3 complexes (Tang et al. 2011). Interestingly, Thr179 phosphorylation of Smad3 by CDK8 or CDK9, in combination with an adjacent PY motif in the $\mathrm{MH} 2$ domain is a prerequisite for this monoubiquitylation.

\section{Deubiquitylation of $R$-Smads}

Ubiquitylation is a reversible process. Deubiquitylating enzymes (DUBs) oppose the effects of ubiquitylation on Smads. Ubiquitin specific peptidase (USP15) is a DUB that removes monoubiquitylation of Smad3 and thus enhances the occupancy of target promoters by Smad complexes (Inui et al. 2011). Silencing the expression of USP15 consequently impairs the recruitment of TGF- $\beta$-activated Smad complexes to regulatory DNA sequences of target genes and inhibits TGF- $\beta$ response in cell growth arrest, cell migration, and Xenopus embryonic germ layers induction and patterning (Inui et al. 2011). Cylindromatosis (CYLD), turban tumor syndrome, a DUB in the NF- $\mathrm{KB}$ pathway, also inhibits TGF- $\beta$ signaling and lung fibrosis by decreasing the stability of Smad3 as a result of the CYLD-mediated Akt deubiquitylation and the release of Akt-mediated inhibition of GSK3 $\beta$-CHIP-induced Smad3 degradation ( $\mathrm{Lim}$ et al. 2012). Interestingly, OTU domain-containing ubiquitin aldehyde-binding protein 1 (OTUB1) a member of ovarian tumor (OTU) family of DUBs, inhibits TGF$\beta$-induced Smad2 and Smad3 ubiquitylation by blocking the E2 ubiquitin-conjugating enzyme, independently of its catalytic activity (Herhaus et al. 2013). These observations suggest a dynamic balance of monoubiquitylation and deubiquitylation in the control of R-Smad activities.

Other Posttranslational Modifications of R-Smads

\section{Sumoylation of R-Smads}

Sumoylation covalently attaches a small ubiquitin-like modifier (SUMO) polypeptide that structurally resembles ubiquitin to a lysine residue of protein substrate, and occurs primarily on perinuclear and nuclear proteins including transcription factors (Kerscher et al. 2006). Su- 
Posttranslational Regulation of Smads

moylation usually does not lead to degradation of targeted proteins, but often regulates their subcellular localization, protein associations, and functions. Smad3 was found to associate with a protein inhibitor of activated STATy (PIASy, also known as PIAS4), a nuclear matrix-associated SUMO E3 ligase, and to be sumoylated leading to a suppressed activity of Smad3 (Imoto et al. 2003). Intriguingly, knockdown of Ubc9, the only SUMO E2 ligase, reduces the accumulation of phospho-Smad3 during the pathogenesis of fibrosis and has an antifibrosis effect in either T $\beta$ RI or bleomycin-induced dermal fibrosis model, suggesting a functional significance of sumoylation in canonical TGF- $\beta$ signaling (Khodzhigorova et al. 2012).

\section{Acetylation of R-Smads}

In addition to phosphorylation and ubiquitylation, Smad2 and Smad3 are also acetylated at lysine residues in response to TGF- $\beta$. The acetylation results from TGF- $\beta$-induced association of the transcription coactivators CAMPresponse element-binding (CREB)-protein (CBP) and p300, which possess intrinsic acetyltransferase activity, with Smad2 and Smad3. Smad2 is primarily acetylated in its $\mathrm{MH} 1$ domain, whereas Smad3 is acetylated in its $\mathrm{MH} 2$ domain, although both acetylations enhance Smad-mediated transcription (Simonsson et al. 2006; Inoue et al. 2007; Tu and Luo 2007). Thus, coactivator-mediated acetylation of R-Smads in the nucleus represents an additional avenue to modulate TGF- $\beta$ signaling. The detailed characterization and underlying mechanisms of how acetylation alters the activity of the R-Smad complex and changes the selectivity of Smad partners/coregulators are still not clear.

\section{ADP-Ribosylation of R-Smads}

ADP-ribosylation is another type of protein modification that adds one or more ADP-ribose moieties to arginine residue by the ADP-ribosyltransferase, and regulates various cell signaling and cellular processes. Smad3 can be ADP-ribosylated in its $\mathrm{MH} 1$ domain through the action of poly (ADP-ribose) polymerase-1
(PARP-1), which results in dissociation of Smad3/4 complexes from DNA. As a result, PARP-1 attenuates Smad-mediated TGF- $\beta$ responses, and cells with PARP-1 overexpression show impaired Smad3-mediated gene responses and TGF- $\beta$-induced epithelial-mesenchymal transition (EMT) (Lönn et al. 2010). Thus, ADP-ribosylation of Smad proteins may serve as another mechanism to control the intensity and duration of Smad-mediated transcription. Whether ADP-ribosylation also occurs on other R-Smad molecules is to be determined.

\section{POSTTRANSLATIONAL REGULATION OF THE Co-Smad, Smad4}

Smad4, the common Smad for all R-Smads that consequently controls Smad signaling of the entire TGF- $\beta$ family signaling, functions as a transcription co-activator that associates with R-Smads and enhances the effectiveness of R-Smad-mediated transcription (Feng et al. 1998; Heldin and Moustakas 2012). The gene encoding Smad4 is frequently altered in cancers and other diseases, which can lead to impaired responsiveness to TGF- $\beta$-imposed growth inhibition. Like R-Smads, the activities of Smad4 are stringently modulated by PTMs, including phosphorylation, ubiquitylation, and sumolyation, all of which define the Smad4 interactome, its subcellular localization, and its stability (Fig. 2).

\section{Phosphorylation of Smad4}

Constitutive phosphorylation of Smad4 has been observed in cells, although not all the phosphorylation sites have been identified. Erk kinases phosphorylate Smad4 specifically at Thr276 in the linker region, and this phosphorylation stabilizes the binding of the coactivators p300 and CBP to the heteromeric Smad complex (Roelen et al. 2003). Therefore, the substitution of Thr276 to alanine leads to decreased nuclear localization of Smad4 and a reduced Smad-mediated transcriptional response. In addition to constitutive phosphorylation, Smad4 phosphorylation is also regulated by signal stimulation (Wrighton et al. 2009a). 
P. Xu et al.

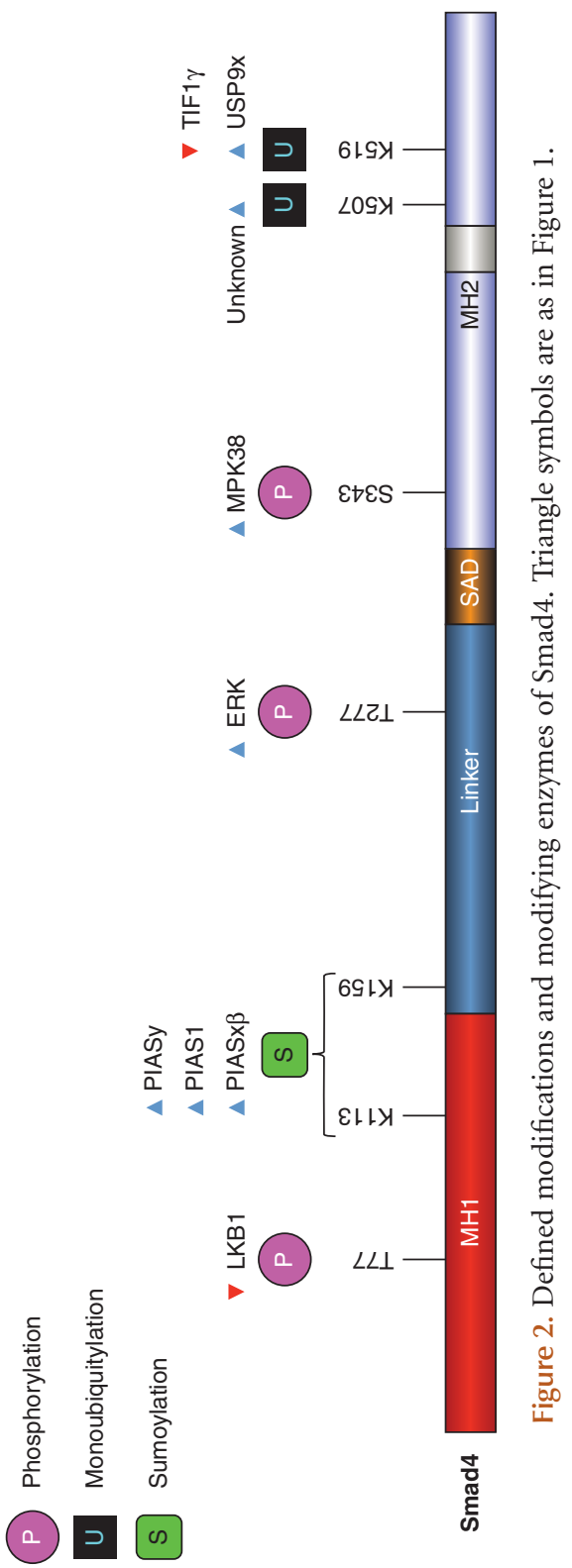


For example, the liver kinase B1 (LKB1), also known as STK11, which regulates cell polarity and is required in the control of cell metabolism, phosphorylates Thr77 in the MH1 domain of Smad4. This phosphorylation interferes with Smad4 binding to either TGF- $\beta$ or BMP-specific promoter sequences, and inhibits Smad-mediated gene expression and TGF- $\beta$ induced EMT (Morén et al. 2011). In contrast, phosphorylation of Smad4 by the serine/threonine kinase MPK38, known to activate p53 function, is thought to enhance TGF- $\beta$ signaling and TGF- $\beta$-induced apoptosis and cell growth arrest (Seong et al. 2010).

Phosphorylation of several cancer-associated Smad4 mutants appears to be a prerequisite for ubiquitylation of Smad4 by the SCF complex, and leads to their accelerated proteolysis (Liang et al. 2004a). For example, the R100T, G65V, and L43S mutation in the MH1 domain of Smad4 leads to enhanced phosphorylation of Smad 4 by JNK/p38 MAPK, and consequently increased affinity of mutant Smad4 for $\mathrm{SCF}^{\beta \mathrm{TrCP}}$ and SCF ${ }^{\text {Skp2 }}$ (Liang et al. 2004a). Similar mutations of Smad4 in acute myelogenous leukemia or pancreatic cancer cause a rapid proteasomal degradation of Smad4, mediated by $\mathrm{SCF}^{\beta \operatorname{TrCP}}$ (Yang et al. 2006). Additionally, hyperactive Ras has also been shown to drive the degradation of Smad4 in intestinal epithelial cells through Erk MAPK activity and an unidentified ubiquitin E3 ligase, which represses TGF$\beta$-activated transcriptional responses (Saha et al. 2001).

\section{Ubiquitylation of Smad4}

\section{Polyubiquitylation and Degradation of Smad4}

Like R-Smads, Smad4 is also targeted for polyubiquitylation that often leads to its degradation. Smad4 stability is controlled by three families of E3 ligases: RING-finger SCF complex, HECT-domain, and PHD-finger E3 ligases (Liang et al. 2004a; Wan et al. 2004; Dupont et al. 2005). SCF ${ }^{\beta \operatorname{TrCP} 1}$ promotes ubiquitylation and degradation of Smad4, and antagonizes TGF- $\beta$ function. The E3 ligase activity of $\mathrm{SCF}^{\beta \operatorname{TrCP} 1}$ is facilitated by the direct association of Smad4 with Jun activating binding protein 1 (Jab1), a component of the COP9 signalosome (Wan et al. 2004). Another member of the SCF family E3 ligases, $\mathrm{SCF}^{\text {Skp2 }}$, has no effect on the stability of wild-type Smad4 but only targets cancer-derived Smad4 mutants for increased ubiquitylation and accelerated degradation (Liang et al. 2004a). The HECT family E3 ligases, the Smurfs, polyubiquitylate Smad4 and promote the proteasomal degradation of Smad4 (Morén et al. 2005). Because Smad4 lacks a PY motif and cannot directly associate with HECT domain E3 ligases, I-Smads serve as adaptors for the recruitment of Smurfs to Smad4. Furthermore, a single-subunit RING E3 ligase TRIM33/TIF1 $\gamma$, also named ectodermin, has similarly been shown to specifically bind to Smad4, and reduce the level of nuclear Smad4 in the ectoderm by targeting Smad4 for ubiquitylation and proteosomal degradation. Thus, overexpression of TRIM33/ectodermin results in a low level of TGF- $\beta$ signaling and indirectly promotes the mesodermal fate $(\mathrm{Du}-$ pont et al. 2005). However, TRIM33/TIF1 $\gamma$ was also reported to compete with Smad4 in binding TGF- $\beta$-activated Smad 2 and Smad3, and to direct Smad4-independent transcription that regulates erythroid differentiation $(\mathrm{He}$ et al. 2006). The PHD-bromodomain of TRIM33/ TIF1 $\gamma$ also facilitates its binding to H3K9me3 and $\mathrm{H} 3 \mathrm{~K} 18 \mathrm{ac}$ at the promoters of mesendoderm regulators, which subsequently displaces the chromatin-compacting factor HP1 $\gamma$ (heterochromatin protein $1 \gamma$ ), and makes nodal-responsive DNA elements accessible to Smad complexes. At the same time, recruitment of RNA polymerase II to this DNA-Smad complex site enhances the expression of mesendoderm regulators goosecoid (Gsc) and Mix-like homeodomain protein 1 (Mixl1), and thus controls the mesendodermal differentiation of embryonic stem cells (ESCs) (Agricola et al. 2011; $\mathrm{Xi}$ et al. 2011). Like $\mathrm{SCF}^{\beta \operatorname{TrCP}}$ and $\mathrm{SCF}^{\text {Skp2 }}$, TRIM33/TIF1 $\gamma$ also shows increased expression in tumors, suggesting that destruction of Smad4 may play a key role in tumorigenesis. In addition, the presence of more than one E3 ligase targeting Smad4 for degradation 
P. Xu et al.

highlights the critical role of Smad4 in mediating TGF- $\beta$ signaling in normal or diseased cells.

\section{Monoubiquitylation of Smad4}

Monoubiquitylation also regulates the signaling and transcription functions of Smad4. TRIM33/TIF1 $\gamma$ was shown to monoubiquitylate Smad4 at Lys519 in the MH2 domain (Morén et al. 2003), thus preventing Smad4 association with activated Smad2/3 (Dupont et al. 2009). Smad4 Lys519 monoubiquitylation imposed by TRIM33/TIF1 $\gamma$ can be removed by the deubiquitylase FAM/USP9x, which consequently restores $\mathrm{Smad} 4$ function in the contexts of TGF- $\beta$-induced growth inhibition and cell migration (Dupont et al. 2009). Interestingly, three naturally occurring amino acid mutations in Smad4 that were detected in cancer cells are located near this monoubiquitylation site in Smad4, and result in defective monoubiquitylation of Smad4, which may lead to Myhre syndrome, a developmental retardation disorder (Le Goff et al. 2012). In contrast, FOXM1, a forkhead box family transcription factor that possesses strong oncogenic activity, interacts with Smad3 and interferes with TRIM33/ TIF1 $\gamma$ binding to the Smad3/4 complex. The reduced binding of TRIM33/TIF1 $\gamma$ to the Smad complex attenuates Smad4 monoubiquitylation by TRIM33/TIF1 $\gamma$, and thus stabilizes Smad3/4 complex formation and facilitates TGF- $\beta$-dependent promotion of cancer metastasis (Xue et al. 2014). On the other hand, Smad4 monoubiquitylation at Lys507 may enhance the complex formation of Smad4 with activated R-Smads (Morén et al. 2003). This Lys507, conserved among all members of the Smad family, resides in the L3 loop region of Smad4's MH2 domain and is responsible for Smad4 recognition of the phospho-SSXS motif of R-Smads during Smad heterotrimer formation. The substitution of Lys 507 with Arg blocks the nuclear accumulation and transcriptional responses of Smad4 (Morén et al. 2003). However, the E3 ligase(s) that catalyze(s) Smad4 monoubiquitylation at Lys507 have not been identified.
Other Posttranslational Modifications of Smad4

\section{Sumoylation of Smad4}

SUMO-1 and Ubc9, the only E2 sumoylation ligase, were identified as Smad4-interacting proteins in yeast two-hybrid screens (Lee et al. 2003; Lin et al. 2003b). Furthermore, Smad4 is sumoylated on Lys113 and Lys159, and sequence comparison suggests that sumoylation of Smad4 is highly conserved throughout evolution (Lee et al. 2003; Lin et al. 2003b).

The effects of sumoylation on Smad4 are multifaceted. Smad4 sumoylation may prevent Smad4 from ubiquitylation, thus protecting Smad4 from degradation to enhance TGF- $\beta$ induced Smad signaling. Accordingly, the sumoylated form of Smad4 confers enhanced growth inhibition and transcriptional responses in mammalian cells and Xenopus embryos (Lee et al. 2003; Lin et al. 2003a,b). However, Smad4 sumoylation was also reported to repress Smadmediated transcription by recruiting Daxx (Fas death domain-associated protein), initially identified as Fas-interacting protein to regulate cell apoptosis, to Smad4 at regulatory promoter sequences, thus inhibiting the intrinsic transactivation capability of Smad4 (Long et al. 2004; Chang et al. 2005). This apparent contradiction might be because of the use of different promoter sequences as models, and needs further study in physiological contexts. Remarkably, the activity of TRIM33/TIF1 $\gamma$ as transcriptional corepressor and as a Smad4 substitute in TGF- $\beta$ signaling under some circumstances (Dupont et al. 2009) also requires sumoylation of its Smadinteracting domain to regulate TGF- $\beta$ signaling and inhibit TGF- $\beta$-regulated EMT (Fattet et al. 2013). Smad4 sumoylation requires a PIAS protein as the E3 ligase, and PIAS1, PIASx $\beta$, and PIASy were shown to bind to Smad4 and promote Smad4 sumoylation (Ohshima and Shimotohno 2003; Liang et al. 2004b; Long et al. 2004). Consistent with these observations, PIAS1 mutants that lack a functional RING domain but retain the Smad4-binding domain, can block Smad4 sumoylation and TGF- $\beta$ transcriptional responses in a dominant-negative manner (Liang et al. 2004b). 
Intriguingly, Smad4 sumoylation is lost in several cancer-derived Smad4 mutants, especially those with missense mutations in $\mathrm{MH1}$ domain (Lin et al. 2003a). As mentioned, these cancer mutants show enhanced phosphorylation, preferentially by JNK or p38 MAPK, which results in an increased affinity for $\mathrm{SCF}^{\mathrm{Skp} 2}$ $\mathrm{SCF}^{\beta \operatorname{TrCP}} \mathrm{E} 3$ ligases and subsequent ubiquitylation and degradation (Liang et al. 2004a; Wan et al. 2004; Wan et al. 2005). These observations support the notion that the cancer-associated mutations in the MH1 domain can switch Smad4 from being sumoylated to being ubiquitylated, and lead to loss of Smad4 activity.

\section{ADP-Ribosylation of Smad4}

Similar to Smad2 and Smad3, Smad4 is also ADP-ribosylated by PARP-1 in its DNA-binding MH1 domain, which interferes with Smad4 DNA binding and attenuates Smad-mediated transcription and induction of EMT (Lönn et al. 2010). Stimulated dissociation of Smad complexes from DNA by PTMs represents an intriguing mode for terminating Smad signaling. It is worthwhile to further investigate whether other modifications lead to similar scenarios in regulating TGF- $\beta$ family signaling.

\section{Naturally Occurring Mutations in Smad4}

Consistent with its critical role in mediating TGF- $\beta$ function, alterations of the SMAD4 gene frequently occur in human cancers and other diseases. Although many SMAD4 mutations or deletions affect the sequence encoding the MH2 domain and render Smad4 inactive in driving Smad signaling, a number of cancer-associated SMAD4 missense mutations, primarily in the sequence encoding the $\mathrm{MH} 1$ domain, cause an accelerated degradation of Smad4 (Morén et al. 2000; Xu and Attisano 2000). For example, the R100T missense mutation of Smad4 in pancreatic cancers results in a faster degradation, whereas, likewise, Smad4 with MH1 domain mutations, such as L43S, G65V, and P130L, are also unstable (Xu and Attisano 2000). These cancer cell-derived Smad4 mutants show higher affinity for SCF ${ }^{\text {Skp2 }}$ and $\mathrm{SCF}^{\beta \mathrm{TrCP}} \mathrm{E} 3$ ligases, which are also oncogenic and often are up-regulated in cancer cells (Liang et al. 2004a). As mentioned, these Smad4 mutants show increased phosphorylation by JNK and p38 MAPKs, leading to enhanced ubiquitylation and degradation. Therefore, pharmacological inhibition of JNK or p38 MAP kinases can prevent the degradation of Smad4 mutants to the same extent as proteasomal inhibitors (Liang et al. 2004a). The accelerated degradation of these cancer-derived mutants may be a mechanism to ensure complete removal of residual tumor suppressor activity of Smad4. In conclusion, the function and stability of Smad4 are extensively regulated by PTM, which provides high versatility to Smad signaling.

\section{REGULATION OF I-Smads}

The expression and activities of the two I-Smads in vertebrates, Smad6 and Smad7, represent a critical level of negative control of TGF- $\beta$ signaling. I-Smads shuttle continuously between nucleus and cytoplasm allowing for an inhibitory feedback loop in multiple compartments (Heldin and Moustakas 2012). Several mechanisms enable I-Smad-mediated inhibition of TGF- $\beta$ family signaling, including competitive interference with activation of R-Smads by activated type I receptors (Hayashi et al. 1997; Imamura et al. 1997; Nakao et al. 1997), inhibition of formation of Smad complexes (Hata et al. 1998), and direct repression of target gene promoters in the nucleus (Bai et al. 2000; Lin et al. 2003c; Zhang et al. 2007). Additionally, Smad7 binding to T $\beta R I$ allows for recruitment of the E3 ubiquitin ligases Smurf1, Smurf2, or WWP1 to the receptor complex, resulting in ubiquitylation and degradation of T $\beta R I$ or BMP type I receptors (Kavsak et al. 2000; Komuro et al. 2004). Binding of Smad7 to the type I receptor can also recruit the GADD34-PP1c phosphatase complex to reverse activation of T $\beta R I$, thereby terminating TGF- $\beta$ responses, such as TGF- $\beta$-induced cell-cycle arrest (Shi et al. 2004b). The phosphatase PP1 regulatory subunit GADD34 has been reported to play an important role in endoplasmic reticulum (ER) 
P. Xu et al.

stress-induced cell death (Kojima et al. 2003). It will be interesting to determine the connection between TGF- $\beta$ signaling and ER stress-induced cellular responses (Tanjore et al. 2011). In addition to repression of TGF- $\beta$ signaling, Smad7 can also act as a transcription factor in the nucleus (Pulaski et al. 2001; Zhang et al. 2007), and an adaptor protein essential for TGF- $\beta$-induced activation of p38 MAPK signaling. Consequently, Smad7 promotes TGF$\beta$-induced, Smad3-independent inactivation of GSK3 $\beta$, nuclear accumulation of $\beta$-catenin, and recruitment of the tumor suppressor adenomatous polyposis coli (APC) to the microtubule plus end, all of which might control TGF$\beta$-stimulated migratory response (Ekman et al. 2012). Reflecting the functional diversity of I-Smads, the level and activity of Smad6 and Smad7 are extensively regulated both at the transcriptional level and through PTMs (Fig. 3).

\section{Complexity in the Regulation of I-Smad Gene Expression}

Distinct from other Smads, the expression of ISmads is regulated by a number of hormones, growth factors and cytokines, which consequently also control TGF- $\beta$ signaling. As a direct negative feedback mechanism, TGF- $\beta$ directly induces Smad7 expression resulting from binding of Smad3/4 complexes to Smad7 gene regulatory sequences (Derynck and Zhang 2003). Activation of Erk, JNK or p38 MAPK signaling all result in transcriptional activation of the Smad7 gene, thus dampening TGF- $\beta$ signaling (Guo and Wang 2009). Some cytokines, such as interferon- $\gamma$ or interleukin-7, induce Smad7 expression through activation of Jak/ STAT signaling (Ulloa et al. 1999; Huang et al. 2002), whereas tumor necrosis factor- $\alpha$ or interleukin- $1 \beta$ induce $S m a d 7$ expression through the NF- $\kappa$ B pathway (Bitzer et al. 2000), leading to inhibition of TGF- $\beta /$ Smad-mediated transcription responses. As a result, recombinant interleukin-7 alleviates bleomycin-induced pulmonary fibrosis in vivo (Huang et al. 2002). Additionally, hypoxia also induces Smad7 expression, mediated by activation of expression of the transcription factor HIF1 $\alpha$ (hypoxia in- ducible factor $1 \alpha$ ), which contributes to malignant cell invasiveness (Heikkinen et al. 2010a).

Smad7 expression is additionally controlled by miRNAs, which reflects another layer of complexity in the regulation of I-Smad expression. miR-106b-25, which derives from a polycistron that is frequently activated by genomic amplification in multiple cancer types and suppresses p $21^{\text {Cip1 }}$ expression, inhibits Smad7 expression and enhances TGF- $\beta$ signaling in epithelial cells and human breast cancer cells. miR-106b-25 expression is up-regulated by Six1, a metastatic regulator. The miR-106b-25 cluster targets Smad7 mRNA, resulting in increased TGF- $\beta$ type I receptor levels and TGF$\beta$ signaling, and induction of EMT (Smith et al. 2012). Similarly, miR-21, a miRNA that targets some tumor suppressor genes such as PTEN and $\mathrm{Bcl} 2$, also decreases Smad7 expression and enhances TGF- $\beta$ signaling (Liu et al. 2010; Smith et al. 2012). During induction of lung fibrosis, TGF- $\beta$ directly induces the expression of miR-21, which in turn inhibits the expression of Smad7. This miR-21-mediated decline of Smad7 expression represses Smad7-mediated negative feedback of TGF- $\beta$ signaling, allowing for prolonged TGF- $\beta$ effects in inducing fibrogenic activation of pulmonary fibroblasts.

\section{Ubiquitylation and Deubiquitylation of I-Smads \\ Polyubiquitylation and Degradation of I-Smads}

Besides regulation at the transcriptional level, I-Smad levels are tightly regulated at the protein level, mainly through ubiquitylation and degradation. Several E3 ligases, such as Smurfs and WWP1/2, have been implicated in this regulation (Soond and Chantry 2011). In the case of Smurf2, the Smad7-Smurf2 complex is formed in the nucleus through a paired interaction between a WW motif in Smurf2 and a PY motif in Smad7, allowing for direct association of the amino-terminal sequence of Smad7 and the HECT domain of Smurf2 (Ogunjimi et al., 2005). This complex is subsequently exported from the nucleus and translocated to the plasma 
Posttranslational Regulation of Smads
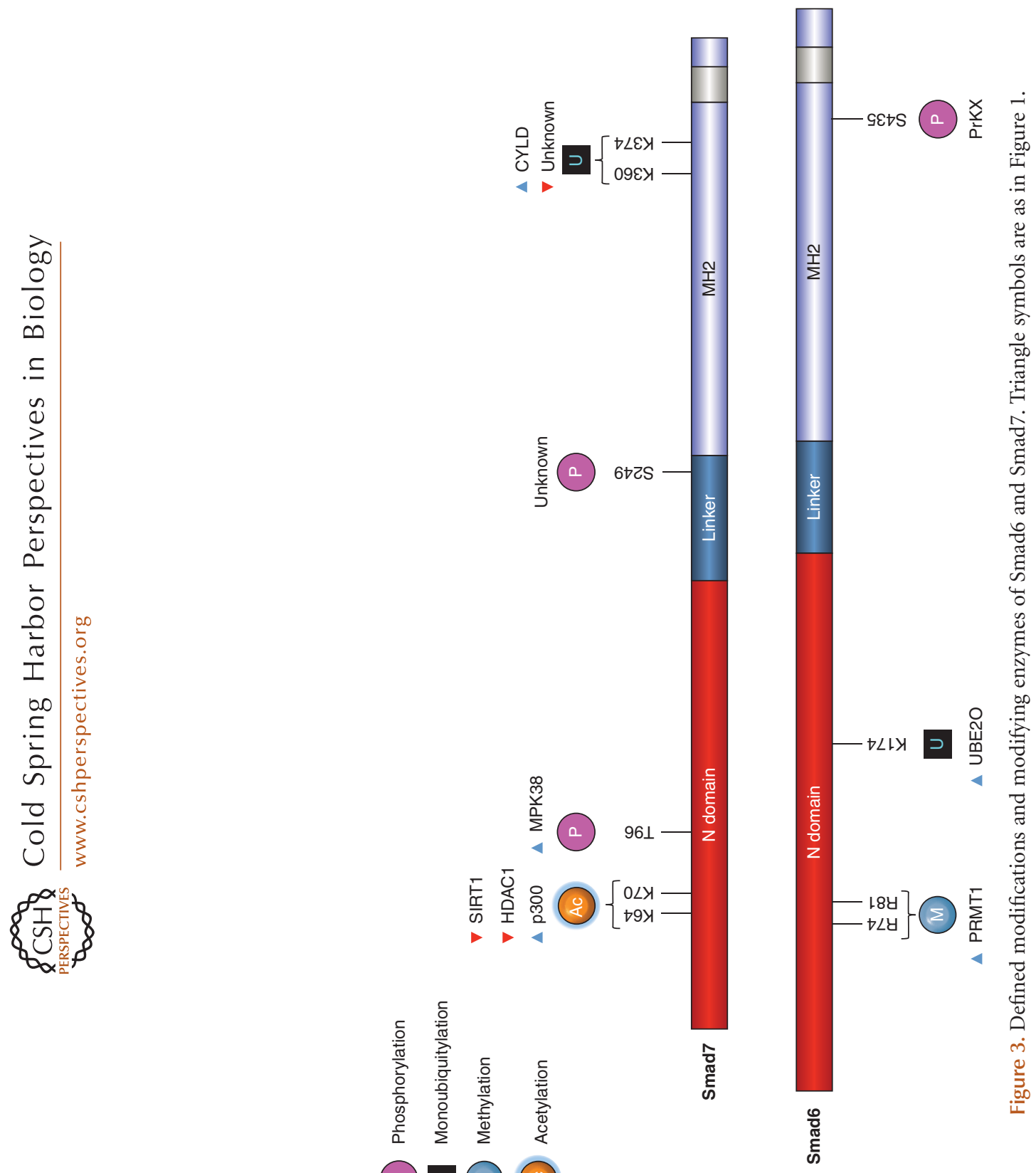
P. Xu et al.

membrane (Suzuki et al. 2002; Tajima et al. 2003). Smad7 is then degraded by Smurf 2 in conjunction with TGF- $\beta$ receptor activation, most likely as Smurf2 targets the receptorSmad7 complex for degradation. Through association with Axin, Smad7 is also targeted by Arkadia/RNF111 E3 ligase, which results in Smad7 degradation and increased TGF- $\beta$ signaling (Liu et al. 2006). In colorectal cancer, the effect of Arkadia on Smad7 degradation and subsequently enhanced TGF- $\beta$ signaling may provide a basis for the tumor suppressor functions of Arkadia (Sharma et al. 2011). In addition, Jab1/CSN5, a component of the COP9 signalosome complex, also interacts with Smad7 and facilitates Smad7 nuclear export for degradation, thereby relieving the inhibitory role of Smad7 on TGF- $\beta$ target gene responses in the nucleus (Kim et al. 2004).

\section{Monoubiquitylation of I-Smads}

Monoubiquitylation of I-Smads also regulates I-Smad activity. During adipogenesis, the putative E2 ubiquitin-conjugating enzyme UBE2O is found to interact with Smad6, and functions as an E2-E3 hybrid to monoubiquitylate Smad6 at Lys174 (Zhang et al. 2013). This modification impairs Smad6 binding to BMP type I receptor, thus potentiating BMP-7 signaling and BMP-7-induced adipocyte differentiation.

\section{Deubiquitylation of I-Smads}

Deubiquitylation of Smad7 occurs through various DUBs. In addition to indirectly regulating Smad3 stability (Lim et al. 2012), as already discussed, the K63-specific deubiquitylase CYLD forms a complex with Smad7 and deubiquitylates Smad7 at K360 and K374, which dampens Smad7-facilitated activation of TAK1 and $\mathrm{p} 38$, and impairs Treg differentiation (Zhao et al. 2011). Two other DUBs, namely, ubiquitin carboxyl-terminal hydrolase 37 (UCH37), also known as UCHL5, and USP15, can interact with Smad7 through the MH1 domain on Smad7, and thus are recruited to T $\beta R I$, where UCH37 and USP15 remove the polyubiquitin chains attached to T $\beta$ RI by Smurfs, and thus stabilize
T $\beta$ RI to up-regulate TGF- $\beta$-dependent transcriptional responses (Wicks et al. 2005; Eichhorn et al. 2012). Notably, USP15 amplification confers poor prognosis of glioblastoma patients, whereas depletion or inhibition of USP15 reduces the oncogenic capacity of patient-derived glioma-initiating cells caused by repressed TGF- $\beta$ signaling (Eichhorn et al. 2012). Intriguingly, Smad6 can also recruit A20, a DUB for TRAF6, allowing A20 to abolish K63-linked polyubiquitylation of TRAF6 and thus prevent TGF- $\beta$-induced activation of p38 MAPK and JNK signaling and apoptosis in hepatocytes (Jung et al. 2013). In conclusion, the ubiquitylation and deubiquitylation of I-Smads further show the complexity of the control of TGF- $\beta$ responses by I-Smads.

\section{Other Posttranslational Modifications of I-Smads \\ Acetylation and Deacetylation of I-Smads}

The activity of Smad7 is also modulated by acetylation and deacetylation. Interaction of Smad7 with the transcriptional coactivator p300, a histone acetyltransferase, results in direct Smad7 acetylation on Lys64 and Lys70 through the intrinsic acetyltransferase activity of p300 (Grönroos et al. 2002). As these same lysine residues are also targeted by ubiquitylation, their acetylation prevents Smurf-mediated ubiquitylation and subsequent degradation of Smad7 (Grönroos et al. 2002). These two lysines are not present in Smad6, indicating a mechanistic difference in ubiquitylation-dependent regulation between Smad6 and Smad7 (Grönroos et al. 2002). Furthermore, the histone deacetylases HDAC1 and SIRT1 can interact with the MH1 domain of Smad7 and reverse Smad7 acetylation, thus enhancing Smurf1-mediated Smad7 ubiquitylation and degradation, and consequently attenuating TGF- $\beta$-induced mesangial cell apoptosis (Simonsson et al. 2005; Kume et al. 2007). The competition between acetylation and ubiquitylation likely controls Smad7 stability inside the nucleus. In addition, the presence of Smad7 in the nucleus and its acetylation by p300 suggest that Smad7 may func- 
tion as a transcription factor (Itoh et al. 1998). Smad7 shows TGF- $\beta$-independent transactivation activity, which is regulated by Ser249 phosphorylation by a yet unidentified kinase (Pulaski et al. 2001). Consistent with the possible role of I-Smads in transcription, Smad6 can directly recruit the corepressor CtBP to the $I d 1$ promoter, or perhaps other BMP-responsive promoters, to regulate BMP signaling (Lin et al. 2003c).

\section{Phosphorylation of I-Smads}

Only a few observations of I-Smad phosphorylation have been reported. PrKX, a kinase that controls macrophage differentiation, can phosphorylate Smad6 in its MH2 domain, and this phosphorylation is required for phorbolmyristate acetate (PMA)-induced differentiation of HL-60 cell into macrophages (Glesne and $\mathrm{Hu}-$ berman 2006). Additionally, MPK38-mediated phosphorylation of Smad7 on Thr96 promotes redistribution of Smad7 to the cytoplasm (Seong et al. 2010), whereas Ser249 phosphorylation by an unknown kinase enhances the transcriptional activity of Smad7 without affecting TGF- $\beta$ signaling (Pulaski et al. 2001).

\section{Methylation of I-Smads}

Monomethylation, asymmetric, and symmetric dimethylation of arginines in proteins often regulates protein function in a temporal-spatial fashion. Based on mass spectrometric analysis, Smad6 was shown to be methylated by the arginine methyltransferase PRMT1 (Inamitsu et al. 2006). Arg methylation of Smad6 by PRMT1 serves as a first critical step in initiating BMP signaling through Smads. Specifically, in response to BMP, PRMT1-mediated methylation of Arg74 and Arg81 residues in Smad6 promotes the release of Smad6 from the BMP receptor complex, allowing for Smad1 activation through carboxy-terminal phosphorylation by BMP type I receptors. Thus, signaling initiation through Arg methylation may explain the slow kinetics of Smad activation, and defines PRMT1 as a positive regulator of BMPinduced Smad activation (Xu et al. 2013). Notably, the involvement of PRMT1 in BMP- induced biological responses is evolutionarily conserved as PRMT1 regulates wing development in Drosophila (Xu et al. 2013). Therefore, arginine methylation, which is mostly known to regulate gene expression through histone methylation, can also regulate the TGF- $\beta$ and BMP signaling pathways by direct modification of ISmads.

\section{CONCLUDING REMARKS}

Although TGF- $\beta$ family signaling through Smads is a conceptually simple and linear pathway, it allows for amazing versatility and context dependence of the TGF- $\beta$ family responses. Like many key regulatory proteins, the expression and activities of Smads are regulated at different levels including by PTMs (Fig. 4). Increasing evidence emphasizes the fundamental roles of phosphorylation, ubiquitylation, sumoylation, and acetylation in Smad regulation. Through their effects on the activity, stability, and interactome of Smads, these PTMs finely tune TGF- $\beta$ family responses and define the intensity and versatility of TGF- $\beta$ family responsiveness in pathophysiological processes.

Moving forward, systematic studies under physiological conditions are needed to explore additional modification sites of all Smads, the corresponding modifying enzymes, and their regulation and functional consequences. Such studies also require sensitive modern methodologies, such as mass spectrometry, chromatinimmunoprecipitation (ChIP)-seq, deep RNA sequencing, and bioinformatics, in combination with detailed mechanistic studies. Finally, it is vitally important to identify additional and novel modifications, such as lipidation, nitrosylation, neddylation, and carbon-chain modifications, and reveal the synergistic or opposing effects of different types of modifications at multiple sites. Because most modifications are reversible, identification and characterization of respective enzymes, and the interacting proteins that control their catalytic activities, will provide further insights into the functions of these modifications in TGF- $\beta$ pathophysiology. In conclusion, advances in characterizing of novel modifiers and modification modes will reveal a 
P. Xu et al.

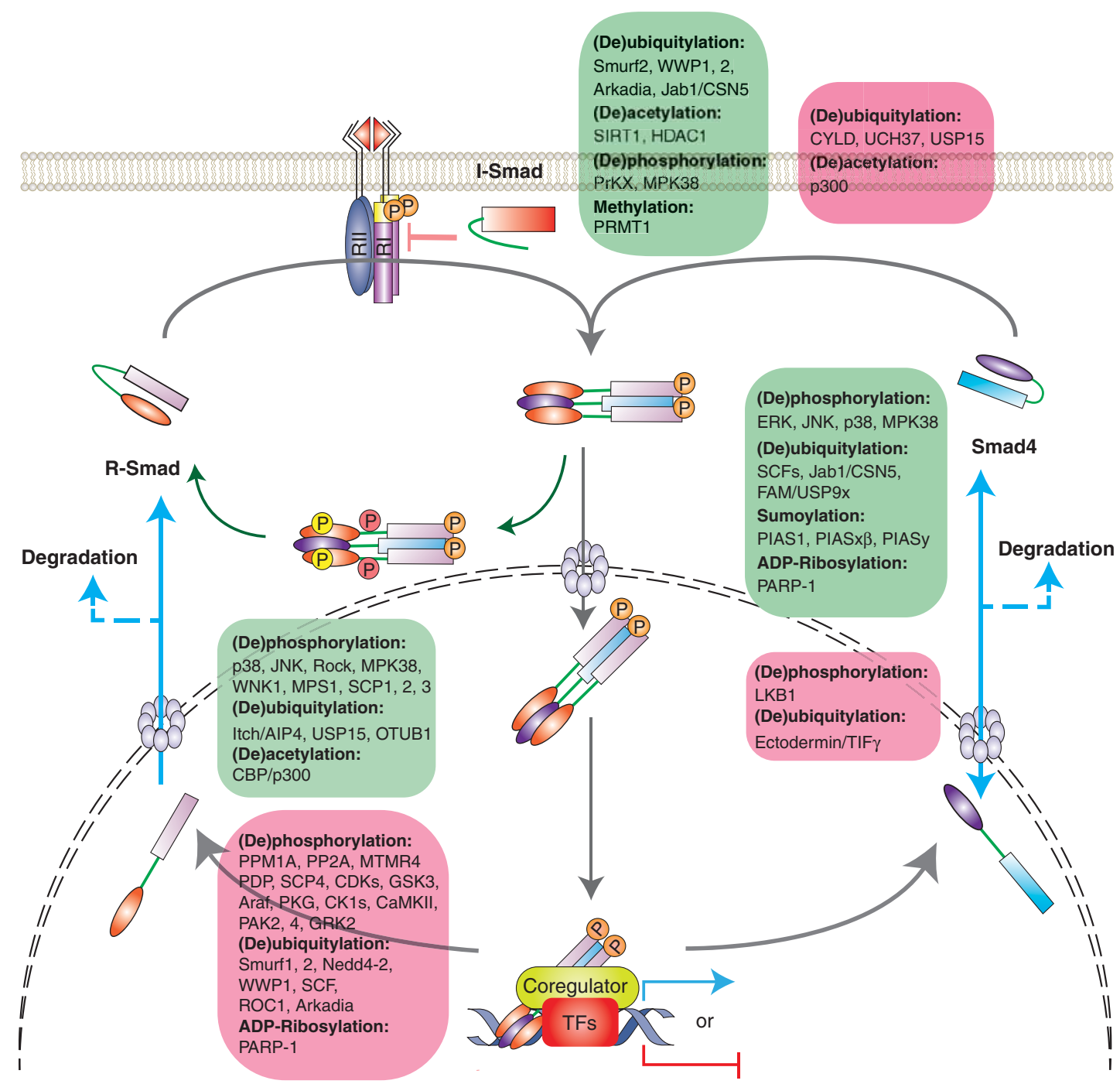

Figure 4. Roles of posttranslational modifications (PTMs) in transforming growth factor $\beta$ (TGF- $\beta$ ) family signaling. Modifications and modifying enzymes that promote or inhibit Smad signaling are indicated.

clearer picture of the activities of TGF- $\beta$ family proteins.

\section{ACKNOWLEDGMENTS}

This review of recent advances requires that we limit ourselves to selected observations to illustrate the roles of Smad posttranslational modifications. Many exciting findings could not be included. We therefore apologize to those researchers whose work was not included in this review. The research described in the authors' laboratories was partly supported by grants from the Ministry of Science and Technology (MOST) (2012CB966600, 2015CB553800), Natural Science Foundation of China (NSFC) (91540205, 31571447, 31090360), Department of Defense (DoD) (1W81XWH-15-1-0650), National Institutes of Health (NIH) (R01G M63773, R01AR053591, R01CA108454) to X.-H.F; MOST (2015CB553800) and NSFC (81472665) to P.X.; NIH (R01DK073932) to 
X.L.; Project 111; Project 985; and the Fundamental Research Funds for the Central Universities to the Life Sciences Institute at Zhejiang University.

\section{REFERENCES}

Agricola E, Randall RA, Gaarenstroom T, Dupont S, Hill CS 2011. Recruitment of TIF1 $\gamma$ to chromatin via its PHD finger-bromodomain activates its ubiquitin ligase and transcriptional repressor activities. Mol Cell 43: 85-96.

Alarcon C, Zaromytidou AI, Xi Q, Gao S, Yu J, Fujisawa S, Barlas A, Miller AN, Manova-Todorova K, Macias MJ, et al. 2009. Nuclear CDKs drive Smad transcriptional activation and turnover in BMP and TGF- $\beta$ pathways. Cell 139: $757-769$.

Aragon E, Goerner N, Zaromytidou AI, Xi Q, Escobedo A, Massagué J, Macias MJ. 2011. A Smad action turnover switch operated by WW domain readers of a phosphoserine code. Genes Dev 25: 1275-1288.

Atfi A, Dumont E, Colland F, Bonnier D, L'Helgoualc'h A, Prunier C, Ferrand N, Clement B, Wewer UM, Theret N. 2007. The disintegrin and metalloproteinase ADAM12 contributes to TGF- $\beta$ signaling through interaction with the type II receptor. J Cell Biol 178: 201-208.

Aubin J, Davy A, Soriano P. 2004. In vivo convergence of BMP and MAPK signaling pathways: impact of differential Smad1 phosphorylation on development and homeostasis. Genes Dev 18: 1482-1494.

Bae E, Sato M, Kim RJ, Kwak MK, Naka K, Gim J, Kadota M, Tang B, Flanders KC, Kim TA, et al. 2014. Definition of Smad3 phosphorylation events that affect malignant and metastatic behaviors in breast cancer cells. Cancer Res 74: 6139-6149.

Bai S, Shi X, Yang X, Cao X. 2000. Smad6 as a transcriptional corepressor. J Biol Chem 275: 8267-8270.

Bai Y, Yang C, Hu K, Elly C, Liu YC. 2004. Itch E3 ligasemediated regulation of TGF- $\beta$ signaling by modulating Smad2 phosphorylation. Mol Cell 15: 825-831.

Bharathy S, Xie W, Yingling JM, Reiss M. 2008. Cancerassociated transforming growth factor $\beta$ type II receptor gene mutant causes activation of bone morphogenic protein-Smads and invasive phenotype. Cancer Res 68: 1656-1666.

Bitzer M, von Gersdorff G, Liang D, Dominguez-Rosales A, Beg AA, Rojkind M, Bottinger EP. 2000. A mechanism of suppression of TGF- $\beta /$ SMAD signaling by NF- $\kappa$ B/RelA. Genes Dev 14: 187-197.

Bonni S, Wang HR, Causing CG, Kavsak P, Stroschein SL, Luo K, Wrana JL. 2001. TGF- $\beta$ induces assembly of a Smad2-Smurf2 ubiquitin ligase complex that targets SnoN for degradation. Nat Cell Biol 3: 587-595.

Bourgeois B, Gilquin B, Tellier-Lebegue C, Ostlund C, Wu W, Perez J, El Hage P, Lallemand F, Worman HJ, ZinnJustin S. 2013. Inhibition of TGF- $\beta$ signaling at the nuclear envelope: Characterization of interactions between MAN1, Smad2 and Smad3, and PPM1A. Sci Signal 6: ra49.

Bu S, Kapanadze B, Hsu T, Trojanowska M. 2008. Opposite effects of dihydrosphingosine 1-phosphate and sphingo- sine 1-phosphate on transforming growth factor- $\beta$ / Smad signaling are mediated through the PTEN/ PPM1A-dependent pathway. J Biol Chem 283: $19593-$ 19602.

Chang CC, Lin DY, Fang HI, Chen RH, Shih HM. 2005. Daxx mediates the small ubiquitin-like modifier-dependent transcriptional repression of Smad4. J Biol Chem 280: 10164-10173.

Chen HB, Shen J, Ip YT, Xu L. 2006. Identification of phosphatases for Smad in the BMP/DPP pathway. Genes Dev 20: 648-653.

Chen F, Lin X, Xu P, Zhang Z, Chen Y, Wang C, Han J, Zhao B, Xiao M, Feng XH. 2015. Nuclear export of Smads by RanBP3L regulates bone morphogenetic protein signaling and mesenchymal stem cell differentiation. $\mathrm{Mol}$ Cell Biol 35: 1700-1711.

Dai F, Lin X, Chang C, Feng XH. 2009. Nuclear export of Smad 2 and Smad 3 by RanBP3 facilitates termination of TGF- $\beta$ signaling. Dev Cell 16: 345-357.

Dai F, Shen T, Li Z, Lin X, Feng XH. 2011. PPM1A dephosphorylates RanBP3 to enable efficient nuclear export of Smad2 and Smad3. EMBO Rep 12: 1175-1181.

Daly AC, Randall RA, Hill CS. 2008. Transforming growth factor $\beta$-induced Smad $1 / 5$ phosphorylation in epithelial cells is mediated by novel receptor complexes and is essential for anchorage-independent growth. Mol Cell Biol 28: 6889-6902.

Derynck R, Zhang YE. 2003. Smad-dependent and Smadindependent pathways in TGF- $\beta$ family signalling. $\mathrm{Na}$ ture 425: 577-584.

Duan X, Liang YY, Feng XH, Lin X. 2006. Protein serine/ threonine phosphatase PPM1A dephosphorylates Smad1 in the bone morphogenetic protein signaling pathway. J Biol Chem 281: 36526-36532.

Dupont S, Zacchigna L, Cordenonsi M, Soligo S, Adorno M, Rugge M, Piccolo S. 2005. Germ-layer specification and control of cell growth by Ectodermin, a Smad4 ubiquitin ligase. Cell 121: 87-99.

Dupont S, Mamidi A, Cordenonsi M, Montagner M, Zacchigna L, Adorno M, Martello G, Stinchfield MJ, Soligo S, Morsut L, et al. 2009. FAM/USP9x, a deubiquitinating enzyme essential for TGF $\beta$ signaling, controls Smad4 monoubiquitination. Cell 136: 123-135.

Eichhorn PJ, Rodon L, Gonzalez-Junca A, Dirac A, Gili M, Martinez-Saez E, Aura C, Barba I, Peg V, Prat A, et al. 2012. USP15 stabilizes TGF- $\beta$ receptor I and promotes oncogenesis through the activation of TGF- $\beta$ signaling in glioblastoma. Nat Med 18: 429-435.

Ekman M, Mu Y, Lee SY, Edlund S, Kozakai T, Thakur N, Tran H, Qian J, Groeden J, Heldin CH, et al. 2012. APC and Smad7 link TGF $\beta$ type I receptors to the microtubule system to promote cell migration. Mol Biol Cell 23: 2109_ 2121.

Engel ME, McDonnell MA, Law BK, Moses HL. 1999. Interdependent SMAD and JNK signaling in transforming growth factor- $\beta$-mediated transcription. $J$ Biol Chem 274: 37413-37420.

Fattet L, Ay AS, Bonneau B, Jallades L, Mikaelian I, Treilleux I, Gillet G, Hesling C, Rimokh R. 2013. TIF1 $\gamma$ requires sumoylation to exert its repressive activity on TGF $\beta$ signaling. J Cell Sci 126: 3713-3723. 
P. Xu et al.

Feng XH, Derynck R. 2005. Specificity and versatility in tgf$\beta$ signaling through Smads. Annu Rev Cell Dev Biol 21: 659-693.

Feng XH, Lin X. 2006. Regulation of Smad functions through ubiquitination and sumoylation pathways. In Smad signal transduction (ed. ten Dijke P, Heldin C-H), pp. 253-276. Springer, Dordrecht, The Netherlands.

Feng XH, Zhang Y, Wu RY, Derynck R. 1998. The tumor suppressor Smad4/DPC4 and transcriptional adaptor $\mathrm{CBP} / \mathrm{p} 300$ are coactivators for smad 3 in TGF- $\beta$-induced transcriptional activation. Genes Dev 12: 2153-2163.

Fuentealba LC, Eivers E, Ikeda A, Hurtado C, Kuroda H, Pera EM, De Robertis EM. 2007. Integrating patterning signals: Wnt/GSK3 regulates the duration of the BMP/ Smad1 signal. Cell 131: 980-993.

Fukasawa H, Yamamoto T, Togawa A, Ohashi N, Fujigaki Y, Oda T, Uchida C, Kitagawa K, Hattori T, Suzuki S, et al. 2004. Down-regulation of Smad7 expression by ubiquitin-dependent degradation contributes to renal fibrosis in obstructive nephropathy in mice. Proc Natl Acad Sci 101: $8687-8692$.

Fukuchi M, Imamura T, Chiba T, Ebisawa T, Kawabata M, Tanaka K, Miyazono K. 2001. Ligand-dependent degradation of Smad3 by a ubiquitin ligase complex of Roc1 and associated proteins. Mol Biol Cell 12: 1431-1443.

Fukuchi M, Fukai Y, Masuda N, Miyazaki T, Nakajima M, Sohda M, Manda R, Tsukada K, Kato H, Kuwano H. 2002. High-level expression of the Smad ubiquitin ligase Smurf2 correlates with poor prognosis in patients with esophageal squamous cell carcinoma. Cancer Res 62: $7162-7165$.

Funaba M, Zimmerman CM, Mathews LS. 2002. Modulation of Smad2-mediated signaling by extracellular signalregulated kinase. J Biol Chem 277: 41361-41368.

Galliher AJ, Schiemann WP. 2007. Src phosphorylates Tyr284 in TGF- $\beta$ type II receptor and regulates TGF- $\beta$ stimulation of p38 MAPK during breast cancer cell proliferation and invasion. Cancer Res 67: 3752-3758.

Gao S, Alarcon C, Sapkota G, Rahman S, Chen PY, Goerner N, Macias MJ, Erdjument-Bromage H, Tempst P, Massagué J. 2009. Ubiquitin ligase Nedd4L targets activated Smad2/3 to limit TGF- $\beta$ signaling. Mol Cell 36: $457-$ 468.

Glesne D, Huberman E. 2006. Smad6 is a protein kinase X phosphorylation substrate and is required for HL-60 cell differentiation. Oncogene 25: 4086-4098.

Goumans MJ, Valdimarsdottir G, Itoh S, Rosendahl A, Sideras P, ten Dijke P. 2002. Balancing the activation state of the endothelium via two distinct TGF- $\beta$ type I receptors. EMBO J 21: 1743-1753.

Goumans MJ, Valdimarsdottir G, Itoh S, Lebrin F, Larsson J, Mummery C, Karlsson S, ten Dijke P. 2003. Activin receptor-like kinase (ALK) 1 is an antagonistic mediator of lateral TGFß/ALK5 signaling. Mol Cell 12: 817-828.

Grönroos E, Hellman U, Heldin CH, Ericsson J. 2002. Control of Smad7 stability by competition between acetylation and ubiquitination. Mol Cell 10: 483-493.

Guo X, Wang XF. 2009. Signaling cross-talk between TGF$\beta /$ BMP and other pathways. Cell Res 19: 71-88.
Guo X, Ramirez A, Waddell DS, Li Z, Liu X, Wang XF. 2008a. Axin and GSK3- control Smad3 protein stability and modulate TGF- $\beta$ signaling. Genes Dev 22: 106-120.

Guo X, Waddell DS, Wang W, Wang Z, Liberati NT, Yong S, Liu X, Wang XF. 2008b. Ligand-dependent ubiquitination of Smad3 is regulated by casein kinase $1 \gamma 2$, an inhibitor of TGF- $\beta$ signaling. Oncogene 27: 7235-7247.

Hata A, Lagna G, Massagué J, Hemmati-Brivanlou A. 1998. Smad6 inhibits BMP/Smad1 signaling by specifically competing with the Smad4 tumor suppressor. Genes Dev 12: 186-197.

Hayashi H, Abdollah S, Qiu Y, Cai J, Xu YY, Grinnell B, Richardson M, Topper J, Gimbrone M Jr, Wrana JL, et al. 1997. The MAD-related protein Smad7 associates with the TGF $\beta$ receptor and functions as an antagonist of the TGF $\beta$ signaling. Cell 89: 1165-1173.

He W, Dorn DC, Erdjument-Bromage H, Tempst P, Moore MA, Massagué J. 2006. Hematopoiesis controlled by distinct TIF1 $\gamma$ and Smad4 branches of the TGF $\beta$ pathway. Cell 125: 929-941.

Heikkinen PT, Nummela M, Jokilehto T, Grenman R, Kahari VM, Jaakkola PM. 2010a. Hypoxic conversion of SMAD7 function from an inhibitor into a promoter of cell invasion. Cancer Res 70: 5984-5993.

Heikkinen PT, Nummela M, Leivonen SK, Westermarck J, Hill CS, Kahari VM, Jaakkola PM. 2010b. Hypoxia-activated Smad3-specific dephosphorylation by PP2A. J Biol Chem 285: 3740-3749.

Heldin CH, Moustakas A. 2012. Role of Smads in TGF $\beta$ signaling. Cell Tissue Res 347: 21-36.

Herhaus L, Al-Salihi M, Macartney T, Weidlich S, Sapkota GP. 2013. OTUB1 enhances TGF $\beta$ signalling by inhibiting the ubiquitylation and degradation of active SMAD2/3. Nat Commun 4: 2519.

Ho J, Cocolakis E, Dumas VM, Posner BI, Laporte SA, Lebrun JJ. 2005. The G protein-coupled receptor kinase-2 is a TGF $\beta$-inducible antagonist of TGF $\beta$ signal transduction. EMBO J 24: 3247-3258.

Horiki M, Imamura T, Okamoto M, Hayashi M, Murai J, Myoui A, Ochi T, Miyazono K, Yoshikawa H, Tsumaki N. 2004. Smad6/Smurf1 overexpression in cartilage delays chondrocyte hypertrophy and causes dwarfism with osteopenia. J Cell Biol 165: 433-445.

Huang M, Sharma S, Zhu LX, Keane MP, Luo J, Zhang L, Burdick MD, Lin YQ, Dohadwala M, Gardner B, et al. 2002. IL-7 inhibits fibroblast TGF- $\beta$ production and signaling in pulmonary fibrosis. J Clin Invest 109: 931-937.

Huse M, Muir TW, Xu L, Chen YG, Kuriyan J, Massagué J. 2001. The TGF $\beta$ receptor activation process: An inhibitor- to substrate-binding switch. Mol Cell 8: 671-682.

Imamura T, Takase M, Nishihara A, Oeda E, Hanai J, Kawabata M, Miyazono K. 1997. Smad6 inhibits signalling by the TGF- $\beta$ superfamily. Nature 389: 622-626.

Imoto S, Sugiyama K, Muromoto R, Sato N, Yamamoto T, Matsuda T. 2003. Regulation of transforming growth factor- $\beta$ signaling by protein inhibitor of activated STAT, PIASy through Smad3. J Biol Chem 278: 34253-34258.

Inamitsu M, Itoh S, Hellman U, Ten Dijke P, Kato M. 2006. Methylation of Smad6 by protein arginine $N$-methyltransferase 1. FEBS Lett 580: 6603-6611. 
Inman GJ, Nicolas FJ, Hill CS. 2002. Nucleocytoplasmic shuttling of Smads 2, 3, and 4 permits sensing of TGF$\beta$ receptor activity. Mol Cell 10: 283-294.

Inoue Y, Itoh Y, Abe K, Okamoto T, Daitoku H, Fukamizu A, Onozaki K, Hayashi H. 2007. Smad3 is acetylated by p300/CBP to regulate its transactivation activity. Oncogene 26: 500-508.

Inui M, Manfrin A, Mamidi A, Martello G, Morsut L, Soligo S, Enzo E, Moro S, Polo S, Dupont S, et al. 2011. USP15 is a deubiquitylating enzyme for receptor-activated SMADs. Nat Cell Biol 13: 1368-1375.

Itoh S, Landstrom M, Hermansson A, Itoh F, Heldin $\mathrm{CH}$ Heldin NE, ten Dijke P. 1998. Transforming growth factor $\beta 1$ induces nuclear export of inhibitory Smad7. J Biol Chem 273: 29195-29201.

Izzi L, Attisano L. 2004. Regulation of the TGF $\beta$ signalling pathway by ubiquitin-mediated degradation. Oncogene 23: 2071-2078.

Jung SM, Lee JH, Park J, Oh YS, Lee SK, Park JS, Lee YS, Kim JH, Lee JY, Bae YS, et al. 2013. Smad6 inhibits non-canonical TGF- $\beta 1$ signalling by recruiting the deubiquitinase A20 to TRAF6. Nat Commun 4: 2562.

Kamaraju AK, Roberts AB. 2005. Role of Rho/ROCK and p38 MAP kinase pathways in transforming growth factor$\beta$-mediated Smad-dependent growth inhibition of human breast carcinoma cells in vivo. J Biol Chem 280: 1024-1036.

Kang JS, Saunier EF, Akhurst RJ, Derynck R. 2008. The type I TGF- $\beta$ receptor is covalently modified and regulated by sumoylation. Nat Cell Biol 10: 654-664.

Kavsak P, Rasmussen RK, Causing CG, Bonni S, Zhu H, Thomsen GH, Wrana JL. 2000. Smad7 binds to Smurf2 to form an E3 ubiquitin ligase that targets the TGF $\beta$ receptor for degradation. Mol Cell 6: 1365-1375.

Kerscher O, Felberbaum R, Hochstrasser M. 2006. Modification of proteins by ubiquitin and ubiquitin-like proteins. Annu Rev Cell Dev Biol 22: 159-180.

Khodzhigorova A, Distler A, Lang V, Dees C, Schneider H, Beyer C, Gelse K, Distler O, Schett G, Distler JH. 2012. Inhibition of sumoylation prevents experimental fibrosis. Ann Rheum Dis 71: 1904-1908.

Kim BC, Lee HJ, Park SH, Lee SR, Karpova TS, McNally JG, Felici A, Lee DK, Kim SJ. 2004. Jab1/CSN5, a component of the COP9 signalosome, regulates transforming growth factor $\beta$ signaling by binding to $S \operatorname{mad} 7$ and promoting its degradation. Mol Cell Biol 24: 2251-2262.

Knockaert M, Sapkota G, Alarcon C, Massagué J, Brivanlou AH. 2006. Unique players in the BMP pathway: Small Cterminal domain phosphatases dephosphorylate Smad1 to attenuate BMP signaling. Proc Natl Acad Sci 103: 11940-11945.

Kojima E, Takeuchi A, Haneda M, Yagi A, Hasegawa T, Yamaki K, Takeda K, Akira S, Shimokata K, Isobe K. 2003. The function of GADD34 is a recovery from a shutoff of protein synthesis induced by ER stress: Elucidation by GADD34-deficient mice. FASEB J 17: 1573-1575.

Komuro A, Imamura T, Saitoh M, Yoshida Y, Yamori T, Miyazono K, Miyazawa K. 2004. Negative regulation of transforming growth factor- $\beta$ (TGF- $\beta$ ) signaling by WW domain-containing protein 1 (WWP1). Oncogene 23: 6914-6923.
Korn T, Bettelli E, Oukka M, Kuchroo VK. 2009. IL-17 and Th17 cells. Annu Rev Immunol 27: 485-517.

Kretzschmar M, Doody J, Timokhina I, Massagué J. 1999. A mechanism of repression of TGF $\beta /$ Smad signaling by oncogenic Ras. Genes Dev 13: 804-816.

Kume S, Haneda M, Kanasaki K, Sugimoto T, Araki S, Isshiki K, Isono M, Uzu T, Guarente L, Kashiwagi A, Koya D. 2007. SIRT1 inhibits transforming growth factor $\beta$ induced apoptosis in glomerular mesangial cells via Smad7 deacetylation. J Biol Chem 282: 151-158.

Kuratomi G, Komuro A, Goto K, Shinozaki M, Miyazawa K, Miyazono K, Imamura T. 2005. NEDD4-2 (neural precursor cell expressed, developmentally down-regulated $4-2$ ) negatively regulates TGF- $\beta$ (transforming growth factor- $\beta$ ) signalling by inducing ubiquitin-mediated degradation of Smad 2 and TGF- $\beta$ type I receptor. Biochem J 386: 461-470.

Lawler S, Feng XH, Chen RH, Maruoka EM, Turck CW, Griswold-Prenner I, Derynck R. 1997. The type II transforming growth factor- $\beta$ receptor autophosphorylates not only on serine and threonine but also on tyrosine residues. J Biol Chem 272: 14850-14859.

Lebrin F, Goumans MJ, Jonker L, Carvalho RL, Valdimarsdottir G, Thorikay M, Mummery C, Arthur HM, ten Dijke P. 2004. Endoglin promotes endothelial cell proliferation and TGF- $\beta$ /ALK1 signal transduction. EMBO J 23: 4018-4028.

Lee PS, Chang C, Liu D, Derynck R. 2003. Sumoylation of Smad4, the common Smad mediator of transforming growth factor- $\beta$ family signaling. J Biol Chem 278: 27853-27863.

Lee BH, Chen W, Stippec S, Cobb MH. 2007a. Biological cross-talk between WNK1 and the transforming growth factor $\beta$-Smad signaling pathway. J Biol Chem 282: 17985-17996.

Lee MK, Pardoux C, Hall MC, Lee PS, Warburton D, Qing J, Smith SM, Derynck R. 2007b. TGF- $\beta$ activates Erk MAP kinase signalling through direct phosphorylation of ShcA. EMBO J 26: 3957-3967.

Le Goff C, Mahaut C, Abhyankar A, Le Goff W, Serre V, Afenjar A, Destree A, di Rocco M, Heron D, Jacquemont S, et al. 2012. Mutations at a single codon in Mad homology 2 domain of SMAD4 cause Myhre syndrome. Nat Genet 44: 85-88.

Lehmann K, Janda E, Pierreux CE, Rytomaa M, Schulze A, McMahon M, Hill CS, Beug H, Downward J. 2000. Raf induces TGF $\beta$ production while blocking its apoptotic but not invasive responses: A mechanism leading to increased malignancy in epithelial cells. Genes Dev 14: 2610-2622.

Levy L, Howell M, Das D, Harkin S, Episkopou V, Hill CS. 2007. Arkadia activates Smad3/Smad4-dependent transcription by triggering signal-induced SnoN degradation. Mol Cell Biol 27: 6068-6083.

Liang M, Liang YY, Wrighton $\mathrm{K}$, Ungermannova D, Wang XP, Brunicardi FC, Liu X, Feng XH, Lin X. 2004a. Ubiquitination and proteolysis of cancer-derived Smad4 mutants by SCFSkp2. Mol Cell Biol 24: 7524-7537.

Liang M, Melchior F, Feng XH, Lin X. 2004b. Regulation of Smad4 sumoylation and transforming growth factor- $\beta$ signaling by protein inhibitor of activated STAT1. J Biol Chem 279: 22857-22865. 
P. Xu et al.

Lim JH, Jono H, Komatsu K, Woo CH, Lee J, Miyata M, Matsuno T, Xu X, Huang Y, Zhang W, et al. 2012. CYLD negatively regulates transforming growth factor- $\beta$-signalling via deubiquitinating Akt. Nat Commun 3: 771.

Lin X, Liang M, Feng XH. 2000. Smurf2 is a ubiquitin E3 ligase mediating proteasome-dependent degradation of Smad2 in TGF- $\beta$ signaling. $J$ Biol Chem 275: 36818 36822.

Lin X, Liang M, Liang YY, Brunicardi FC, Feng XH. 2003a. SUMO-1/Ubc9 promotes nuclear accumulation and metabolic stability of tumor suppressor Smad4. J Biol Chem 278: 31043-31048.

Lin X, Liang M, Liang YY, Brunicardi FC, Melchior F, Feng XH. 2003b. Activation of transforming growth factor- $\beta$ signaling by SUMO-1 modification of tumor suppressor Smad4/DPC4. J Biol Chem 278: 18714-18719.

Lin X, Liang YY, Sun B, Liang M, Brunicardi FC, Shi Y, Shi Y, Feng XH. 2003c. Smad6 recruits transcription corepressor CtBP to repress bone morphogenetic protein-induced transcription. Mol Cell Biol 23: 9081-9093.

Lin X, Duan X, Liang YY, Su Y, Wrighton KH, Long J, Hu M, Davis CM, Wang J, Brunicardi FC, et al. 2006. PPM1A functions as a Smad phosphatase to terminate TGF $\beta$ signaling. Cell 125: 915-928.

Liu W, Rui H, Wang J, Lin S, He Y, Chen M, Li Q, Ye Z, Zhang S, Chan SC, et al. 2006. Axin is a scaffold protein in TGF$\beta$ signaling that promotes degradation of Smad7 by $\mathrm{Ar}-$ kadia. EMBO J 25: 1646-1658.

Liu C, Xu P, Lamouille S, Xu J, Derynck R. 2009a. TACEmediated ectodomain shedding of the type I TGF- $\beta$ receptor downregulates TGF- $\beta$ signaling. Mol Cell 35: $26-$ 36.

Liu IM, Schilling SH, Knouse KA, Choy L, Derynck R, Wang XF. 2009b. TGF $\beta$-stimulated Smad1/5 phosphorylation requires the ALK5 L45 loop and mediates the pro-migratory TGF $\beta$ switch. EMBO J 28: 88-98.

Liu G, Friggeri A, Yang Y, Milosevic J, Ding Q, Thannickal VJ, Kaminski N, Abraham E. 2010. miR-21 mediates fibrogenic activation of pulmonary fibroblasts and lung fibrosis. J Exp Med 207: 1589-1597.

Liu X, Xiong C, Jia S, Zhang Y, Chen YG, Wang Q, Meng A. 2013. Araf kinase antagonizes Nodal-Smad2 activity in mesendoderm development by directly phosphorylating the Smad2 linker region. Nat Commun 4: 1728.

Lo RS, Massagué J. 1999. Ubiquitin-dependent degradation of TGF- $\beta$-activated smad2. Nat Cell Biol 1: 472-478.

Long J, Wang G, He D, Liu F. 2004. Repression of Smad4 transcriptional activity by SUMO modification. Biochem J 379: 23-29.

Lönn P, van der Heide LP, Dahl M, Hellman U, Heldin CH, Moustakas A. 2010. PARP-1 attenuates Smad-mediated transcription. Mol Cell 40: 521-532.

Massagué J, Seoane J, Wotton D. 2005. Smad transcription factors. Genes Dev 19: 2783-2810.

Matsuura I, Denissova NG, Wang G, He D, Long J, Liu F. 2004. Cyclin-dependent kinases regulate the antiproliferative function of Smads. Nature 430: 226-231.

Matsuura I, Wang G, He D, Liu F. 2005. Identification and characterization of ERK MAP kinase phosphorylation sites in Smad3. Biochemistry 44: 12546-12553.
Mavrakis KJ, Andrew RL, Lee KL, Petropoulou C, Dixon JE, Navaratnam N, Norris DP, Episkopou V. 2007. Arkadia enhances nodal/TGF- $\beta$ signaling by coupling phosphoSmad2/3 activity and turnover. PLoS Biol 5: e67.

Millet C, Yamashita M, Heller M, Yu LR, Veenstra TD, Zhang YE. 2009. A negative feedback control of transforming growth factor- $\beta$ signaling by glycogen synthase kinase 3-mediated Smad3 linker phosphorylation at Ser204. J Biol Chem 284: 19808-19816.

Morén A, Itoh S, Moustakas A, Dijke P, Heldin CH. 2000. Functional consequences of tumorigenic missense mutations in the amino- terminal domain of Smad4. Oncogene 19: 4396-4404.

Morén A, Hellman U, Inada Y, Imamura T, Heldin CH, Moustakas A. 2003. Differential ubiquitylation defines the functional status of the tumor suppressor Smad4. J Biol Chem 278: 33571-33582.

Morén A, Imamura T, Miyazono K, Heldin CH, Moustakas A. 2005. Degradation of the tumor suppressor Smad4 by WW and HECT domain ubiquitin ligases. $J$ Biol Chem 280: 22115-22123.

Morén A, Raja E, Heldin CH, Moustakas A. 2011. Negative regulation of TGF $\beta$ signaling by the kinase LKB1 and the scaffolding protein LIP1. J Biol Chem 286: 341-353.

Mori S, Matsuzaki K, Yoshida K, Furukawa F, Tahashi Y, Yamagata H, Sekimoto G, Seki T, Matsui H, Nishizawa $\mathrm{M}$, et al. 2004. TGF- $\beta$ and HGF transmit the signals through JNK-dependent Smad2/3 phosphorylation at the linker regions. Oncogene 23: 7416-7429.

Mu Y, Sundar R, Thakur N, Ekman M, Gudey SK, Yakymovych $\mathrm{M}$, Hermansson A, Dimitriou H, BengoecheaAlonso MT, Ericsson J, et al. 2011. TRAF6 ubiquitinates TGF $\beta$ type I receptor to promote its cleavage and nuclear translocation in cancer. Nat Commun 2: 330.

Nakao A, Afrakhte M, Morén A, Nakayama T, Christian J, Heuchel R, Itoh S, Kawabata M, Heldin NH, Heldin CH, ten Dijke P. 1997. Identification of Smad7, a TGF 3 -inducible antagonist of TGF- $\beta$ signalling. Nature 389: 631-635.

Narimatsu M, Bose R, Pye M, Zhang L, Miller B, Ching P, Sakuma R, Luga V, Roncari L, Attisano L, Wrana JL. 2009. Regulation of planar cell polarity by Smurf ubiquitin ligases. Cell 137: 295-307.

Ogunjimi AA, Briant DJ, Pece-Barbara N, Le Roy C, Di Guglielmo GM, Kavsak P, Rasmussen RK, Seet BT, Sicheri F, Wrana JL. 2005. Regulation of Smurf2 ubiquitin ligase activity by anchoring the E2 to the HECT domain. Mol Cell 19: 297-308.

Ohshima T, Shimotohno K. 2003. TGF- $\beta$ mediated signaling via the p38 MAP kinase pathway activates Smad-dependent transcription through SUMO-1 modification of Smad4. J Biol Chem 278: 50833-50842.

Pannu J, Nakerakanti S, Smith E, ten Dijke P, Trojanowska M. 2007. Transforming growth factor- $\beta$ receptor type Idependent fibrogenic gene program is mediated via activation of Smad 1 and ERK1/2 pathways. J Biol Chem 282: 10405-10413.

Pulaski L, Landstrom M, Heldin CH, Souchelnytskyi S. 2001. Phosphorylation of Smad7 at Ser-249 does not interfere with its inhibitory role in transforming growth factor- $\beta$-dependent signaling but affects Smad7-depen- 
dent transcriptional activation. J Biol Chem 276: 1434414349.

Ray D, Terao Y, Nimbalkar D, Chu LH, Donzelli M, Tsutsui T, Zou X, Ghosh AK, Varga J, Draetta GF, et al. 2005. Transforming growth factor $\beta$ facilitates $\beta$-TrCP-mediated degradation of Cdc25A in a Smad3-dependent manner. Mol Cell Biol 25: 3338-3347.

Roelen BA, Cohen OS, Raychowdhury MK, Chadee DN, Zhang Y, Kyriakis JM, Alessandrini AA, Lin HY. 2003. Phosphorylation of threonine 276 in Smad4 is involved in transforming growth factor- $\beta$-induced nuclear accumulation. Am J Physiol Cell Physiol 285: C823-C830.

Saha D, Datta PK, Beauchamp RD. 2001. Oncogenic ras represses transforming growth factor- $\beta /$ Smad signaling by degrading tumor suppressor Smad4. J Biol Chem 276: 29531-29537.

Sapkota G, Knockaert M, Alarcon C, Montalvo E, Brivanlou AH, Massagué J. 2006. Dephosphorylation of the linker regions of Smad 1 and Smad2/3 by small C-terminal domain phosphatases has distinct outcomes for bone morphogenetic protein and transforming growth factor- $\beta$ pathways. J Biol Chem 281: 40412-40419.

Sapkota G, Alarcon C, Spagnoli FM, Brivanlou AH, Massagué J. 2007. Balancing BMP signaling through integrated inputs into the Smad1 linker. Mol Cell 25: 441-454.

Saura M, Zaragoza C, Herranz B, Griera M, Diez-Marques L, Rodriguez-Puyol D, Rodriguez-Puyol M. 2005. Nitric oxide regulates transforming growth factor- $\beta$ signaling in endothelial cells. Circ Res 97: 1115-1123.

Schmierer B, Hill CS. 2005. Kinetic analysis of Smad nucleocytoplasmic shuttling reveals a mechanism for transforming growth factor $\beta$-dependent nuclear accumulation of Smads. Mol Cell Biol 25: 9845-9858.

Schmierer B, Hill CS. 2007. TGFß-SMAD signal transduction: Molecular specificity and functional flexibility. Nat Rev Mol Cell Biol 8: 970-982.

Schmierer B, Tournier AL, Bates PA, Hill CS. 2008. Mathematical modeling identifies Smad nucleocytoplasmic shuttling as a dynamic signal-interpreting system. Proc Natl Acad Sci 105: 6608-6613.

Seo SR, Lallemand F, Ferrand N, Pessah M, L'Hoste S, Camonis J, Atfi A. 2004. The novel E3 ubiquitin ligase Tiull associates with TGIF to target Smad2 for degradation. EMBO J 23: 3780-3792.

Seong HA, Jung H, Ha H. 2010. Murine protein serine/ threonine kinase 38 stimulates TGF- $\beta$ signaling in a kinase-dependent manner via direct phosphorylation of Smad proteins. J Biol Chem 285: 30959-30970.

Sharma V, Antonacopoulou AG, Tanaka S, Panoutsopoulos AA, Bravou V, Kalofonos HP, Episkopou V. 2011. Enhancement of TGF- $\beta$ signaling responses by the E3 ubiquitin ligase Arkadia provides tumor suppression in colorectal cancer. Cancer Res 71: 6438-6449.

Shi Y, Massagué J. 2003. Mechanisms of TGF- $\beta$ signaling from cell membrane to the nucleus. Cell 113: 685-700.

Shi W, Chen H, Sun J, Chen C, Zhao J, Wang YL, Anderson KD, Warburton D. 2004a. Overexpression of Smurf1 negatively regulates mouse embryonic lung branching morphogenesis by specifically reducing Smadl and Smad5 proteins. Am J Physiol Lung Cell Mol Physiol 286: L293-L300.
Shi W, Sun C, He B, Xiong W, Shi X, Yao D, Cao X. 2004b. GADD34-PP1c recruited by Smad7 dephosphorylates TGF $\beta$ type I receptor. J Cell Biol 164: 291-300.

Shukla A, Malik M, Cataisson C, Ho Y, Friesen T, Suh KS, Yuspa SH. 2009. TGF- $\beta$ signalling is regulated by Schnurri-2-dependent nuclear translocation of CLIC4 and consequent stabilization of phospho-Smad2 and 3 . Nat Cell Biol 11: 777-784.

Simonsson M, Heldin CH, Ericsson J, Grönroos E. 2005. The balance between acetylation and deacetylation controls Smad7 stability. J Biol Chem 280: 21797-21803.

Simonsson M, Kanduri M, Grönroos E, Heldin CH, Ericsson J. 2006. The DNA binding activities of Smad2 and Smad3 are regulated by coactivator-mediated acetylation. J Biol Chem 281: 39870-39880.

Smith AL, Iwanaga R, Drasin DJ, Micalizzi DS, Vartuli RL, Tan AC, Ford HL. 2012. The miR-106b-25 cluster targets Smad7, activates TGF- $\beta$ signaling, and induces EMT and tumor initiating cell characteristics downstream of Six 1 in human breast cancer. Oncogene 31: 5162-5171.

Soond SM, Chantry A. 2011. How ubiquitination regulates the TGF- $\beta$ signalling pathway: new insights and new players: New isoforms of ubiquitin-activating enzymes in the E1-E3 families join the game. Bioessays 33: 749758.

Souchelnytskyi S, ten Dijke P, Miyazono K, Heldin $\mathrm{CH}$. 1996. Phosphorylation of Ser 165 in TGF- $\beta$ type I receptor modulates TGF- $\beta 1$-induced cellular responses. EMBO J 15: 6231-6240.

Stroschein SL, Bonni S, Wrana JL, Luo K. 2001. Smad3 recruits the anaphase-promoting complex for ubiquitination and degradation of SnoN. Genes Dev 15: 2822 2836.

Suzuki C, Murakami G, Fukuchi M, Shimanuki T, Shikauchi Y, Imamura T, Miyazono K. 2002. Smurfl regulates the inhibitory activity of Smad7 by targeting Smad7 to the plasma membrane. J Biol Chem 277: 39919-39925.

Tajima Y, Goto K, Yoshida M, Shinomiya K, Sekimoto T, Yoneda Y, Miyazono K, Imamura T. 2003. Chromosomal region maintenance 1 (CRM1)-dependent nuclear export of Smad ubiquitin regulatory factor 1 (Smurf1) is essential for negative regulation of transforming growth factor- $\beta$ signaling by Smad7. J Biol Chem 278: 1071610721.

Tang LY, Zhang YE. 2011. Non-degradative ubiquitination in Smad-dependent TGF- $\beta$ signaling. Cell Biosci 1: 43.

Tang LY, Yamashita M, Coussens NP, Tang Y, Wang X, Li C, Deng CX, Cheng SY, Zhang YE. 2011. Ablation of Smurf2 reveals an inhibition in TGF- $\beta$ signalling through multiple mono-ubiquitination of Smad3. EMBO J 30: 47774789.

Tanjore H, Cheng DS, Degryse AL, Zoz DF, Abdolrasulnia R, Lawson WE, Blackwell TS. 2011. Alveolar epithelial cells undergo epithelial-to-mesenchymal transition in response to endoplasmic reticulum stress. J Biol Chem 286: 30972-30980.

Togawa A, Yamamoto T, Suzuki H, Fukasawa H, Ohashi N, Fujigaki Y, Kitagawa K, Hattori T, Kitagawa M, Hishida A. 2003. Ubiquitin-dependent degradation of Smad2 is increased in the glomeruli of rats with anti-thymocyte serum nephritis. Am J Pathol 163: 1645-1652. 
P. Xu et al.

Tu AW, Luo K. 2007. Acetylation of Smad2 by the co-activator p300 regulates activin and transforming growth factor $\beta$ response. J Biol Chem 282: 21187-21196.

Ulloa L, Doody J, Massagué J. 1999. Inhibition of transforming growth factor- $\beta /$ SMAD signalling by the interferon$\gamma /$ STAT pathway. Nature 397: 710-713.

Wan Y, Liu X, Kirschner MW. 2001. The anaphase-promoting complex mediates TGF- $\beta$ signaling by targeting SnoN for destruction. Mol Cell 8: 1027-1039.

Wan M, Tang Y, Tytler EM, Lu C, Jin B, Vickers SM, Yang L, Shi X, Cao X. 2004. Smad4 protein stability is regulated by ubiquitin ligase SCF $\beta-T r C P 1$. J Biol Chem 279: 14484-14487.

Wan M, Huang J, Jhala NC, Tytler EM, Yang L, Vickers SM, Tang Y, Lu C, Wang N, Cao X. 2005. SCFß-TrCP1 controls Smad4 protein stability in pancreatic cancer cells. Am J Pathol 166: 1379-1392.

Wang G, Matsuura I, He D, Liu F. 2009. Transforming growth factor- $\beta$-inducible phosphorylation of Smad3. J Biol Chem 284: 9663-9673.

Wang C, Li Y, Zhang H, Liu F, Cheng Z, Wang D, Wang G, Xu $\mathrm{H}$, Zhao Y, Cao L, et al. 2014a. Oncogenic PAK4 regulates Smad2/3 axis involving gastric tumorigenesis. Oncogene 33: 3473-3484.

Wang Y, Lei R, Zhuang X, Zhang N, Pan H, Li G, Hu J, Pan X, Tao Q, Fu D, et al. 2014b. DLC1-dependent parathyroid hormone-like hormone inhibition suppresses breast cancer bone metastasis. J Clin Invest 124: 1646-1659.

Wicks SJ, Haros K, Maillard M, Song L, Cohen RE, Dijke PT, Chantry A. 2005. The deubiquitinating enzyme UCH37 interacts with Smads and regulates TGF- $\beta$ signalling. Oncogene 24: 8080-8084.

Wrighton KH, Feng XH. 2008. To (TGF) $\beta$ or not to (TGF) $\beta$ : Fine-tuning of Smad signaling via post-translational modifications. Cell Signal 20: 1579-1591.

Wrighton KH, Willis D, Long J, Liu F, Lin X, Feng XH. 2006. Small C-terminal domain phosphatases dephosphorylate the regulatory linker regions of Smad2 and Smad 3 to enhance transforming growth factor- $\beta$ signaling. J Biol Chem 281: 38365-38375.

Wrighton KH, Lin X, Feng XH. 2009a. Phospho-control of TGF- $\beta$ superfamily signaling. Cell Res 19: $8-20$.

Wrighton KH, Lin X, Yu PB, Feng XH. 2009b. Transforming growth factor $\beta$ can stimulate Smad1 phosphorylation independently of bone morphogenic protein receptors. J Biol Chem 284: 9755-9763.

Xi Q, Wang Z, Zaromytidou AI, Zhang XH, Chow-Tsang LF Liu JX, Kim H, Barlas A, Manova-Todorova K, Kaartinen $\mathrm{V}$, et al. 2011. A poised chromatin platform for TGF- $\beta$ access to master regulators. Cell 147: 1511-1524.

Xin H, Xu X, Li L, Ning H, Rong Y, Shang Y, Wang Y, Fu XY, Chang Z. 2005. CHIP controls the sensitivity of transforming growth factor- $\beta$ signaling by modulating the basal level of Smad3 through ubiquitin-mediated degradation. J Biol Chem 280: 20842-20850.

Xu J, Attisano L. 2000. Mutations in the tumor suppressors Smad 2 and Smad4 inactivate transforming growth factor $\beta$ signaling by targeting Smads to the ubiquitin-proteasome pathway. Proc Natl Acad Sci 97: 4820-4825.

Xu P, Derynck R. 2010. Direct activation of TACE-mediated ectodomain shedding by p38 MAP kinase regulates EGF receptor-dependent cell proliferation. Mol Cell 37: 551566.

Xu L, Kang Y, Col S, Massagué J. 2002a. Smad2 nucleocytoplasmic shuttling by nucleoporins CAN/Nup214 and Nup153 feeds TGF $\beta$ signaling complexes in the cytoplasm and nucleus. Mol Cell 10: 271-282.

Xu L, Kang Y, Col S, Massagué J. 2002b. Smad2 nucleocytoplasmic shuttling by nucleoporins CAN/Nup214 and Nup153 feeds TGF $\beta$ signaling complexes in the cytoplasm and nucleus. Mol Cell 10: 271-282.

Xu P, Liu J, Derynck R. 2012. Post-translational regulation of TGF- $\beta$ receptor and Smad signaling. FEBS Lett 586: 1871-1884.

Xu J, Wang AH, Oses-Prieto J, Makhijani K, Katsuno Y, Pei M, Yan L, Zheng YG, Burlingame A, Bruckner K, et al. 2013. Arginine methylation initiates BMP-induced Smad signaling. Mol Cell 51: 5-19.

Xue J, Lin X, Chiu WT, Chen YH, Yu G, Liu M, Feng XH, Sawaya R, Medema RH, Hung MC, et al. 2014. Sustained activation of SMAD3/SMAD4 by FOXM1 promotes TGF- $\beta$-dependent cancer metastasis. J Clin Invest 124: 564-579.

Yamagata H, Matsuzaki K, Mori S, Yoshida K, Tahashi Y, Furukawa F, Sekimoto G, Watanabe T, Uemura Y, Sakaida $\mathrm{N}$, et al. 2005. Acceleration of Smad2 and Smad3 phosphorylation via c-Jun $\mathrm{NH}_{2}$-terminal kinase during human colorectal carcinogenesis. Cancer Res 65: 157165.

Yamashita M, Ying SX, Zhang GM, Li C, Cheng SY, Deng CX, Zhang YE. 2005. Ubiquitin ligase Smurf1 controls osteoblast activity and bone homeostasis by targeting MEKK2 for degradation. Cell 121: 101-113.

Yan X, Zhang J, Sun Q, Tuazon PT, Wu X, Traugh JA, Chen YG. 2012. p21-activated kinase 2 (PAK2) inhibits TGF- $\beta$ signaling in Madin-Darby canine kidney (MDCK) epithelial cells by interfering with the receptor-Smad interaction. J Biol Chem 287: 13705-13712.

Yang L, Wang N, Tang Y, Cao X, Wan M. 2006. Acute myelogenous leukemia-derived SMAD4 mutations target the protein to ubiquitin-proteasome degradation. Hum Mutat 27: 897-905.

Yu J, Pan L, Qin X, Chen H, Xu Y, Chen Y, Tang H. 2010. MTMR4 attenuates transforming growth factor $\beta$ (TGF $\beta$ ) signaling by dephosphorylating R-Smads in endosomes. J Biol Chem 285: 8454-8462.

Zhang Y, Chang C, Gehling DJ, Hemmati-Brivanlou A, Derynck R. 2001. Regulation of Smad degradation and activity by Smurf2, an E3 ubiquitin ligase. Proc Natl Acad Sci 98: 974-979.

Zhang S, Fei T, Zhang L, Zhang R, Chen F, Ning Y, Han Y, Feng XH, Meng A, Chen YG. 2007. Smad7 antagonizes transforming growth factor $\beta$ signaling in the nucleus by interfering with functional Smad-DNA complex formation. Mol Cell Biol 27: 4488-4499.

Zhang X, Zhang J, Bauer A, Zhang L, Selinger DW, Lu CX, Ten Dijke P. 2013. Fine-tuning BMP7 signalling in adipogenesis by UBE2O/E2-230K-mediated monoubiquitination of SMAD6. EMBO J 32: 996-1007.

Zhao M, Qiao M, Harris SE, Oyajobi BO, Mundy GR, Chen D. 2004. Smurf1 inhibits osteoblast differentiation and bone formation in vitro and in vivo. J Biol Chem 279: $12854-12859$. 
Posttranslational Regulation of Smads

Zhao Y, Thornton AM, Kinney MC, Ma CA, Spinner JJ, Fuss IJ, Shevach EM, Jain A. 2011. The deubiquitinase CYLD targets Smad7 protein to regulate transforming growth factor $\beta$ (TGF- $\beta$ ) signaling and the development of regulatory T cells. J Biol Chem 286: 4052040530.

Zhao Y, Xiao M, Sun B, Zhang Z, Shen T, Duan X, Yu PB, Feng XH, Lin X. 2014. C-terminal domain (CTD) small phosphatase-like 2 modulates the canonical bone morphogenetic protein (BMP) signaling and mesenchymal differentiation via Smad dephosphorylation. J Biol Chem 289: $26441-26450$.
Zhu H, Kavsak P, Abdollah S, Wrana JL, Thomsen GH. 1999. A SMAD ubiquitin ligase targets the BMP pathway and affects embryonic pattern formation. Nature 400: 687-693.

Zhu S, Wang W, Clarke DC, Liu X. 2007. Activation of Mps1 promotes transforming growth factor- $\beta$-independent Smad signaling. J Biol Chem 282: 18327-18338.

Zuo W, Huang F, Chiang YJ, Li M, Du J, Ding Y, Zhang T, Lee HW, Jeong LS, Chen Y, et al. 2013. c-Cbl-mediated neddylation antagonizes ubiquitination and degradation of the TGF- $\beta$ type II receptor. Mol Cell 49: 499-510. 


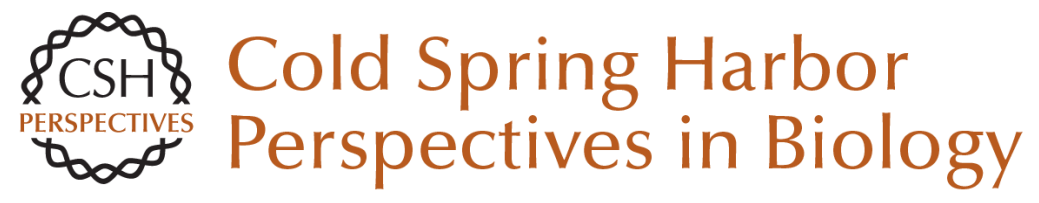

\section{Posttranslational Regulation of Smads}

Pinglong $\mathrm{Xu}$, Xia Lin and Xin-Hua Feng

Cold Spring Harb Perspect Biol 2016; doi: 10.1101/cshperspect.a022087 originally published online October 6, 2016

Subject Collection The Biology of the TGF-\&\#946; Family

TGF- $\beta$ Family Signaling in Early Vertebrate Development Joseph Zinski, Benjamin Tajer and Mary C. Mullins

Bone Morphogenetic Protein-Based Therapeutic Approaches Jonathan W. Lowery and Vicki Rosen

TGF- $\beta$ Family Signaling in Ductal Differentiation and Branching Morphogenesis

Kaoru Kahata, Varun Maturi and Aristidis Moustakas

TGF- $\beta$ Signaling in Control of Cardiovascular

Function

Marie-José Goumans and Peter ten Dijke

TGF- $\beta$ Family Signaling in Tumor Suppression and Cancer Progression

Joan Seoane and Roger R. Gomis

Targeting TGF- $\beta$ Signaling for Therapeutic Gain Rosemary J. Akhurst

Regulation of Hematopoiesis and Hematological Disease by TGF- $\beta$ Family Signaling Molecules Kazuhito Naka and Atsushi Hirao
TGF- $\beta$ Family Signaling in Mesenchymal

Differentiation

Ingo Grafe, Stefanie Alexander, Jonathan $R$. Peterson, et al.

TGF- $\beta 1$ Signaling and Tissue Fibrosis Kevin K. Kim, Dean Sheppard and Harold A. Chapman

Bone Morphogenetic Proteins in Vascular Homeostasis and Disease Marie-José Goumans, An Zwijsen, Peter ten Dijke, et al.

TGF- $\beta$ Family Signaling in Epithelial

Differentiation and Epithelial-Mesenchymal

Transition

Kaoru Kahata, Mahsa Shahidi Dadras and Aristidis Moustakas

TGF- $\beta$ Family Signaling in Connective Tissue and

Skeletal Diseases

Elena Gallo MacFarlane, Julia Haupt, Harry C. Dietz, et al.

The TGF- $\beta$ Family in the Reproductive Tract Diana Monsivais, Martin M. Matzuk and Stephanie A. Pangas

TGF- $\beta$ Family Signaling in Drosophila Ambuj Upadhyay, Lindsay Moss-Taylor, Myung-Jun Kim, et al.

For additional articles in this collection, see http://cshperspectives.cshlp.org/cgi/collection/

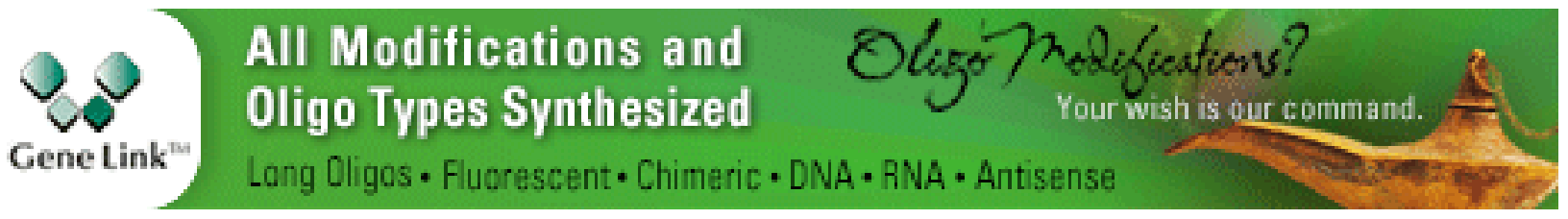


TGF- $\beta$ Family Signaling in Neural and Neuronal Differentiation, Development, and Function Emily A. Meyers and John A. Kessler
Signaling Cross Talk between TGF- $\beta /$ Smad and Other Signaling Pathways Kunxin LuO

For additional articles in this collection, see http://cshperspectives.cshlp.org/cgi/collection/

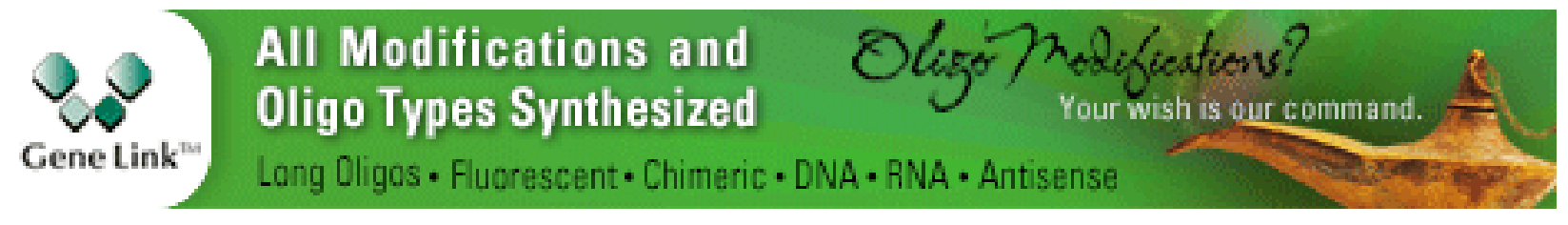

Copyright @ 2016 Cold Spring Harbor Laboratory Press; all rights reserved 